\title{
A new interpretation of the distance puzzle based on geographic neutrality ${ }^{*}$
}

\author{
Iván Arribas ${ }^{\dagger} \quad$ Francisco Pérez ${ }^{\ddagger} \quad$ Emili Tortosa-Ausina ${ }^{\S}$
}

September 29, 2010

\begin{abstract}
One of the most remarkable features of globalization is the fact that advances in technology have contributed to reducing the cost of trade (e.g., transportation and communication costs), and thus boosted international trade. Under these circumstances, the importance of distance should have diminished over time, which would constitute a boon for countries located far from the main centers of economic activity. However, one of the best-established empirical results in international economics is that bilateral trade decreases with distance. This apparent contradiction has been labeled as the "missing globalization puzzle". We propose yet another explanation to this apparent contradiction based on the concept of geographic neutrality, which we use to construct international trade integration indicators for two different scenarios, namely, when distance matters and when it does not. Our results indicate that the importance of distance varies greatly across countries, as revealed by disparate gaps between distance-corrected and distance-uncorrected trade integration indicators for different countries. Some factors rooted in the literature explain away the discrepancies, but their importance varies according to the trade integration indicator considered-trade openness or trade connection.
\end{abstract}

Keywords: Geographic Neutrality, Globalization, Gravity Models, Network Analysis, Remoteness

JEL Classification: F02, F15, Z13

Communications to: Emili Tortosa-Ausina, Departament d'Economia, Universitat Jaume I, Campus del Riu Sec, 12071 Castelló de la Plana, Spain. Tel.: +34 964387168, fax: +34 964728591, e-mail: tortosa@uji.es

\footnotetext{
*This paper is a result of the BBVA Foundation-Ivie Research Program. All authors acknowledge the financial support of the Ministerio de Ciencia e Innovación (SEJ2007-66581, ECO2008-03813/ECON and ECO2008-05908-C02-01/ECON). Francisco Pérez and Emili Tortosa-Ausina also acknowledge the support of Generalitat Valenciana (PROMETEO/2009/066). Emili Tortosa-Ausina also acknowledges the financial support by Fundació Caixa Castelló-BANCAIXA (P1.1B2008-46). All three authors acknowledge the excellent research assistance by Rodrigo Aragón and Pilar Chorén. We also thank the comments by three referees and the editor, David L. Rigby, which have contributed to the overall improvement of the paper. Abel Fernández and participants at the Annual Conference of the European Trade Study Group (Rome, September 2009) provided useful comments which are gratefully acknowledged as well.

${ }^{\dagger}$ Universitat de València, Ivie and ERI-CES.

‡Universitat de València and Ivie.

§Universitat Jaume I and Ivie.
} 


\section{Introduction}

The gravity model of bilateral trade is of primary importance in empirical analyses of trade patterns. Its simplest version states that trade interactions between two geographically defined economic entities (either countries or regions) are proportional to the size of these entities and inversely related to the distance between them (Combes, 2008). The model has been used to further understand the underpinnings of trade flows in general, as well as the role of their particular determinants such as distance, borders, currency unions, WTO membership, insecurity, institutions and a host of others. (Henderson and Millimet, 2008). According to the empirical findings, proximity is the main engine of trade between spatially distinct economic entities. Although this could a priori appear as an obsolete view of the world if one believes in the "death of distance" or the emergence of the "global village" (McLuhan and Fiore, 1968; Combes et al., 2008), there is a widespread reliance on the gravity model based both on its solid theoretical foundation, derived from several underlying theories (see, for instance, Anderson, 1979; Deardorff, 1998; Evenett and Keller, 2002) and the fact that it has proven empirically successful-explaining much of the variation in trade volume over time and space. In their meta-analysis study, Disdier and Head (2008) found that halving distance increased trade by $45 \%$, and more recent analyses by these authors suggest that the distance effect has actually increased in recent years.

Based on these ideas, some authors such as Leamer and Levinsohn (1995) state that the gravity model provides "some of the clearest and most robust empirical findings in economics" (Leamer and Levinsohn, 1995, p.1384), whereas others such as Rose (2000) note that the gravity model provides a "framework with a long track record of success" (Rose, 2000, p.11). Anderson and van Wincoop (2003) concur: “The gravity equation is one of the most empirically successful in economics" (Anderson and van Wincoop, 2003, p.170). This successful performance of the gravity model for explaining bilateral flows has been recently boosted by the availability of a growing number of "natural experiments" in the form of regional trade agreements (Greenaway and Milner, 2002).

As recognized by the literature on international trade, the standard gravity models usually estimated are unable to capture the significant decline in trade costs brought about by the globalization of the world economy. These ideas were initially noted by 
Leamer and Levinsohn (1995), who stated that "the effect of distance on trade patterns is not diminishing over time. Contrary to popular impression, the world is not getting dramatically smaller". Some authors refer to this as the "missing globalization puzzle" (Coe et al., 2002, 2007). Other recent proposals referred to it as "the conservation of distance in international trade" (Berthelon and Freund, 2008), or "the puzzling persistence of the distance effect on bilateral trade" (Disdier and Head, 2008). The question is even more strongly posed when asking whether "distance has died" (Brun et al., 2005), or when stating that "it is alive and well" (Carrere and Schiff, 2005). The number of studies on the issue is substantial. Disdier and Head (2008) provide a useful summary. In their meta-analysis, they conclude that the estimated negative impact of distance on trade rose around the middle of the twentieth century and has remained persistently high since then, with the result holding even after controlling for the heterogeneity in samples and methods across studies.

This debate in the specific area of international economics on the relevance of distance already existed from a more general point of view. In 2005 Thomas Friedman published an influential book, in which he argued that the world is becoming rapidly "flatter", basing his argument on 10 major political, economic and technological phenomena. Although, as indicated by Rodríguez-Pose and Crescenzi (2008), Friedman's "personal eureka" was not particularly new, ${ }^{1}$ it renewed the debate on the topic, as shown by the enormous boost in the number of publications which followed the publication of his book. ${ }^{2}$

In this paper we suggest yet another approach to the "missing globalization puzzle" in the gravity equation. We build on Arribas et al. (2009), who construct indices of international trade integration taking into account some relevant ideas somewhat "forgotten" by the international economics literature, namely, the Standard of Perfect International Integration devised by Frankel (2000), and the concept of geographic neutrality (Kunimoto, 1977; Krugman, 1996). Considering also some ideas derived from network analysis theory, whose importance for trade has been recently revealed by Kali

\footnotetext{
${ }^{1}$ Some other previous and relevant contributions, as suggested by Rodríguez-Pose and Crescenzi (2008), referred to the topic as the "end of geography" (O'brien, 1992), the "death of distance" (Cairncross, 1997), or the emergence of a "space of flows" (Castells, 1998), or of a "weightless economy" (Quah, 1996).

${ }^{2}$ See, for instance, some interesting contributions in the Cambridge Journal of Regions, Economy and Society, mostly made by geographers, such as Christopherson et al. (2008), McCann (2008), Linders et al. (2008), Brakman and van Marrewijk (2008), or Cox (2008).
} 
and Reyes (2007), Arribas et al. (2009) construct an indicator of international trade integration made up of two components that take into account how open to trade and how connected economies are.

Our approach to the better understanding of the missing globalization puzzle is based on a modified version of the indicators of integration proposed by Arribas et al. (2009). Motivated by the robust empirical regularity that bilateral trade flows between pairs of countries are explained well by the product of their gross domestic products (GDPs) and, very importantly, by their bilateral distance, we include the latter when building our measures of trade integration. Specifically, we construct indicators for which both inter-country and intra-country distances are taken into account, since both are relevant for countries' imports and exports as documented not only by the literature on gravity equations (in the case of inter-country distances) but also by Alesina and Spolaore (1997) (in the case of intra-country distances) and, in general, the literature on the "home market effect" hypothesis (big countries produce more of goods with scale economies). The comparison of both sets of indices (distance-corrected and distance-uncorrected) enables us to carry out a new assessment of the role of distance for determining international trade flows.

In contrast to the literature cited above, one of the main advantages of our approach is its ability to enable the effect of distance to vary across countries, considering them individually. Although the idea is not entirely new for geographers, it has barely been explored in the context of trade. A recent contribution which combines ideas from both economic geography and trade is the paper by Boulhol and de Serres (2010), which applies the framework developed by Redding and Venables (2004) on a panel dataset restricted to advanced countries only over the 1970-2004 period. One of their main findings is that the cost of remoteness remains significant. This is a remarkable finding with respect to those of Redding and Venables (2004) which, according to Boulhol and de Serres (2010), led to the false impression that developed countries have escaped the curse of distance. According to Boulhol and de Serres (2010), this occurs because "a crosssection that mixes both low- and high-income countries cannot satisfactorily control for the wide differences in the level of technical efficiency, which drastically biases upwards the sensitivity of GDP per capita to proximity to markets". However, although the study by Boulhol and de Serres (2010) partly addresses the issue that the effect of remoteness 
varies across countries, they only do this partially because countries are clustered into different groups within which heterogeneity is remarkable.

Several geographers have acknowledged this reality (i.e., that the context is critical for the validity of results) from a different point of view. Followers of Casetti $(1972,1991)$ observed in the nineties that the effect of distance varies across countries. This was a specific finding within the more general setting of the expansion method, according to which an explanation (to the extent that it can be achieved) depends on the context. After the initial impetus by Casetti, there was a remarkable increase in research using contextual quantitative models, moving away from traditional approaches which "denied geography" (Jones and Bullen, 1994). ${ }^{3}$ However, the literature has evolved since Jones and Casetti's contributions and, more recently, geographers have shifted to methods such as geographically weighted regression (Fotheringham et al., 2002).

Our proposal is to merge the ways of approaching the globalization puzzle from these two fields of research, i.e., from the trade literature and from the geography literature. ${ }^{4}$ Our approach is particularly effective for dealing with this question because of its ability to construct country-specific indicators of integration with two variants, one which controls for distance and another one that assumes frictionless trade. Therefore, one may identify those countries for which the effect of distance on their trade integration is higher and, in a second stage, to discover some of the covariates that can affect this pattern.

The rest of the article is structured as follows. Section 2 presents the methodological contents of our approach to measure international trade integration, including the estimation method for the distance effect. Section 3 presents the data set and Section 4 the empirical application, by considering data on exports of goods for a wide set of countries that account for most of world output and trade, and for a relatively long sample period (1967-2005). Section 5 explores the determinants of the discrepancies between the original and distance-corrected trade integration indicators. Finally, Section 6 concludes.

\footnotetext{
${ }^{3}$ Eldridge and Jones (1991) are very forceful about this point, stating that "(the distance) parameter has been assumed to be stable across the range of destinations toward which flows are directed. This is a heroic assumption, however, since it suggests that the effect of distance out of a particular origin is unmodified in spite of the diversity of places within the spatial system".

${ }^{4}$ Some recent papers have partly dealt with this issue. For instance, Andresen (2010), with more general aims, summarizes geographers' contributions on trade (we thank a referee for this suggestion).
} 


\section{Defining distance-corrected integration indicators}

Trade openness is not directly observable and there is no theoretical agreement or accepted standard about how to measure it (Epstein et al., 2007). The literature has grown up proposing and evaluating alternative measures to capture this concept, which have been summarized by Proudman et al. (1997), among others. One of the most widespread alternatives are ex post measures such as export shares. ${ }^{5}$ Although these measures have some disadvantages derived from endogeneity in growth regressions and related contexts, given their popularity and straightforwardness we choose them as an initial approach to measure openness and, therefore, the first component of international trade integration that we consider is a modified version of one of the most standard ex post measures of trade integration, namely, total trade (exports, $X$, plus imports, $M$, divided by $G D P$, i.e., $(X+M) / G D P)$.

We argue that trade openness is only but one component of trade integration. If we think of world trade as a network where the nodes are countries and the ties are trade flows among them, we can construct a second component derived from the inclusion of the structure of the current trade relations between countries-what some authors have labeled the "architecture" of trade flows (Kali and Reyes, 2007), or the World Trade Web (WTW). Relevant aspects of this architecture would include the number of trade partners, the proportionality of trade flows to the size of the partners, and the role of barriers-particulary distance.

In order to characterize a benchmark of trade integration which controls for the existence of a world trade network, we define an extension of the concept of geographic neutrality (Kunimoto, 1977; Krugman, 1996; Iapadre, 2006) closely related to the Standard of Perfect International Integration (SPII) by Frankel (2000): “geographically neutral" trade exists when country $B^{\prime}$ s share of $A^{\prime}$ 's exports is equal to $B^{\prime}$ s share of gross world product outside $A$ (Krugman, 1996, p.64). This geographic neutrality concept, as we will show later, is deeply rooted in the latest theoretical developments of the gravity

\footnotetext{
${ }^{5}$ Proudman et al. (1997) consider two additional strands for measuring trade openness. The second strand is outcome-based, which evaluates the gap between the actual outcome and the potential outcome without trade barriers, using trade intensity (Leamer, 1988) or price distortion (Pritchett, 1996) measures. The third strand is the incidence-based approach, which attempts to measure openness by direct observation of trade restrictions such as average tariff rates, non-tariff barriers, black market exchange rates, central planning or state monopolies in major exports.
} 
literature, which refers to the trade predictions of a hypothetic frictionless (trade) world. Moreover, our notion of integration is the same as the SPII by Arribas et al. (2009) in that it also verifies the properties of domestic neutrality, direct international neutrality and $\underline{\text { size, }}$ but differs in the consideration of distance as a key factor. More precisely, our definition of SPII integrates the Samuelson's (1954) standard iceberg assumptions, as we consider that the flow between two economies is not only proportional to their relative sizes but also depends inversely on the distance between the economies. In short, under our neutrality assumption the following properties must be verified:

Domestic neutrality: An economy whose domestic demand is proportional to its share of the world economy will have a higher level of integration.

Direct international neutrality: An economy that balances its direct relations with another individual economy, in proportion to their sizes and inversely to their distances, will have a higher level of integration.

Size: The larger the economy is, the more relevant its integration will be for world integration.

In order to analyze the extent to which economies meet the two properties mentioned above, we must define an integration index and measure the gap between the current level of integration and the SPII. We will proceed in three stages, each one defining different indicators.

\subsection{Controlling for distance}

Taking as starting point the integration indicators defined in Arribas et al. (2009), we introduce some variations to allow for the effect of the distance. Let $N$ be the set of economies and let $i$ and $j$ be typical members of this set. Let $Y_{i}$ be the size of economy $i \in N$, for example its GDP, $d_{i j}$ the geographic distance between the economies $i$ and $j$, and $d_{i i}$ economy $i$ 's internal distance. In order to compare economies that are not contiguous, we follow Samuelson's standard "iceberg" assumption considering that if an economy $j$ of size $Y_{j}$ gets as close to economy $i$ as possible, then its size will be reduced to $Y_{j} / d_{i j}^{\theta}$ (i.e., as stated by Samuelson (1954), "only a fraction of ice exported reaches its destination as unmelted ice"), where $\theta$ is a non-negative parameter which measures the impact of distance (the farther away economies are, the greater the reduction, with an intensity that depends on the $\theta$ parameter). In the extreme case in which $\theta=0$ the 
"iceberg" effect fades away.

We define $a_{i}$ as country $i$ 's share of world GDP, i.e., $a_{i}=Y_{i} / \sum_{j \in N} Y_{j}$. We define $r_{i}$ as the economy $i$ 's relative weight with respect to a world economy where the correction by distance has been performed (distance corrected world) i.e., $r_{i}=\left(Y_{i} / d_{i i}^{\theta}\right) / \sum_{j \in N}\left(Y_{j} / d_{i j}^{\theta}\right)$. Notice that: (i) we also consider that there exists an iceberg effect on the domestic economy (due to countries' differing geographic sizes) or, equivalently, that distance-related trade costs exist both for inter- and intra-national trade; (ii) the above definition does not depend on the units of measurement for the distance between economies given that $r_{i}$ can be written as $r_{i}=Y_{i} / \sum_{j \in N}\left(Y_{j} /\left(d_{i j} / d_{i i}\right)^{\theta}\right)$. This expression allows the effect of the geographic distance to be re-interpreted as the one given by a normalized distance matrix between economies where every internal distance of the economies is 1 and the distance from economy $i$ to economy $j$ is $d_{i j} / d_{i i}$, the times the geographic distance between these economies is bigger than the economy $i$ 's internal distance; and (iii) the impact of the distance depends on the $\theta$ parameter. In a world where distance is irrelevant, $\theta=0$ (geographic neutrality) and $r_{i}=a_{i}$.

Given a measurable relationship between economies, we define the flow $X_{i j}$ as the intensity of this relationship between economies $i$ and $j$. The flow between economies can be evaluated through either the imports or the exports of goods, capital, or any other flow measured in the same units as $Y_{i}$. Moreover, in general the flow will be asymmetric, so that $X_{i j}$ will not necessarily be equal to $X_{j i}$, for all $i, j \in N$. Since the trade openness measure already captures the overall orientation towards the trade of a country, the connectedness of an economy will not take into account the inner flows. All definitions in the paper hinge on the flow considered to measure international integration.

\subsection{Definitions}

Our approach to measure integration proceeds in three stages, defining indicators of trade distance-corrected counterparts to those presented in Arribas et al. (2009). ${ }^{6}$ First, we present the degree of openness; second, we present the degree of balanced connection; third, we combine both indicators to construct a single degree of trade integration for each country. In all three cases the indicators are constructed for both the sce-

\footnotetext{
${ }^{6}$ Although the definitions build on Arribas et al. (2009), all the materials presented here are selfcontained.
} 
nario of geographic neutrality (also zero-gravity or frictionless trade) and the scenario in which distance matters, and where we are still far from a "flat world" (Friedman, 2005) or the "global village" (McLuhan and Fiore, 1968). According to the distanceuncorrected indicators, the spatial separation of nations and regions should be of little importance in economic life, whereas according to the distance-corrected indicators it is still an important impediment for international trade integration. Therefore, we are contributing in a different way to the set of tools offered by economic geography to unearthing some of the complex interactions between globalization and spatial inequalities (Combes et al., 2008, p.365). One of the most relevant features of our indicators is that they are country-specific and, consequently, we can temper the statement by Leamer (2007), who claimed that "physically, culturally, and economically, the world is not flat" (Leamer, 2007, p.123). According to the indicators we present below, this sentence does not equally apply to all countries and, therefore we recommend adding "on average" either at the beginning or the end.

\section{Degree of openness}

First we characterize the degree of openness assuming that output is not domesticallybiased-i.e., it is not biased towards domestic demand. In order to remove the domestic (or home) bias we define $\widehat{Y}_{i}$ as the flow from economy $i$ to the world controlling for the weight in the distance-corrected world economy of the economy under analysis: namely, $\widehat{Y}_{i}=Y_{i}-r_{i} Y_{i}$. Then, we define the relative flow or degree of openness:

Definition 1 Given an economy $i \in N$, we define its degree of openness, $D O_{i}^{\theta}$, as

$$
D O_{i}^{\theta}=\frac{\sum_{j \in N} X_{i j}}{\widehat{Y}_{i}}
$$

We write $D O^{\theta}$ instead of $D O_{i}^{\theta}$ when general statements on the degree of openness are being made, or references to the variable itself, which do not hang on any specific economy. The same rule applies to the other indicators.

\section{Degree of balanced connection}

In the second stage we analyze the "trade architecture" (Kali and Reyes, 2007), i.e., whether the connection of one economy with others is proportional to their sizes in 
terms of GDP, ${ }^{7}$ or whether this connection does not show geographical neutrality. Thus, we define the degree of balanced connection $(D B C)$ to measure the discrepancy between the trade volumes in the real world and those corresponding to the SPII.

In the trade network, the relative flow from country $i$ to country $j$ in terms of the total flow of country $i, \alpha_{i j}$, is given by

$$
\alpha_{i j}=\frac{X_{i j}}{\sum_{j \in N} X_{i j}}
$$

(recall that we are assuming $X_{i i}=0$ ). Let $A=\left(\alpha_{i j}\right)$ be the square matrix of relative flows: the component $i j$ of matrix $A$ is $\alpha_{i j}$.

We consider that the distance-corrected world trade web is perfectly connected if the flow (exports) between two countries is proportional to their relative sizes (geographically neutral trade). Thus, if the world trade is neutral (which, following the SPII nomenclature, would be a "perfectly connected world economy"), then the flow from $i$ to $j$ should be equal to $\beta_{i j} \widehat{Y}_{i}$, where

$$
\beta_{i j}=\frac{Y_{j} / d_{i j}^{\theta}}{\sum_{k \in N \backslash i}\left(Y_{k} / d_{i k}^{\theta}\right)}
$$

is the relative weight of economy $j$ in a distance-corrected world where economy $i$ is not considered.

Note that $\sum_{j \in N \backslash i} \beta_{i j}=1$ and that $\beta_{i j}$ is the degree of openness between countries $i$ and $j$ in the "perfectly connected world" (i.e., the world in which trade is geographically neutral), with $\beta_{i i}=0$. Let $B=\left(\beta_{i j}\right)$ be the square matrix of degrees of openness in the geographically neutral trade world ("perfectly connected world"). The literature on the gravity equation considers similar ideas, although it refers to them in a different way since in the absence of trade costs it is possible to predict trade for the frictionless world. More simply, we can refer to this scenario as the frictionless trade.

Analogously to the degree of openness, we construct the distance corrected degree of balanced connection, as follows:

Definition 2 Given an economy $i \in N$, we define the degree of balance connection of $i$,

\footnotetext{
${ }^{7}$ The dependence of both the number and magnitude of exchanges on economy size is the focus of international trade analyses based on gravity models and widely used in the literature (Hummels and Levinsohn, 1995; Feenstra et al., 1998, 2001; Rauch, 1999).
} 
$D B C_{i}^{\theta}$, as

$$
D B C_{i}^{\theta}=\frac{\sum_{j \in N} \alpha_{i j} \beta_{i j}}{\sqrt{\sum_{j \in N}\left(\alpha_{i j}\right)^{2}} \sqrt{\sum_{j \in N}\left(\beta_{i j}\right)^{2}}} .
$$

\section{Degree of integration}

We construct the degree of integration by combining the degree of openness and the degree of balanced connection defined above as follows:

Definition 3 Given an economy $i \in N$, we define its degree of integration, $D I_{i}$, as

$$
D I_{i}^{\theta}=\sqrt{\min \left\{D O_{i}^{\theta}, 1 / D O_{i}^{\theta}\right\} \cdot D B C_{i}^{\theta}}
$$

In all three cases $\left(D O^{\theta}, D B C^{\theta}\right.$ and $\left.D I^{\theta}\right)$, the cases where $\theta=0$ refer to distanceuncorrected indicators, whereas those in which $\theta=1$ are distance-corrected indicators.

Note that for both components of DI we set limits on the integration level achieved. ${ }^{8}$ This has to be done because of some extreme observations. In relation with the gravity equations literature, our indicators consider its two main regressors: namely, the size of the trading partners and the distance between them. Therefore, one of the advantages of our approach is that, instead of providing us with information as to whether these variables are important for trade flows, it will be possible to measure the gap from the scenario of complete trade integration (frictionless trade, or geographic neutral trade) and the current level of integration, under different hypotheses as to the impact of distance.

To characterize the integration of the world economy as a whole, we should consider the share of each economy in the world, $a_{i}$, to define the global indicators as follow,

$$
\begin{aligned}
D G O^{\theta} & =\sum_{i \in N} a_{i} D O_{i}^{\theta}, \\
D G B C^{\theta} & =\sum_{i \in N} a_{i} D B C_{i}^{\theta}, \\
D G I^{\theta} & =\sum_{i \in N} a_{i} D I_{i}^{\theta} .
\end{aligned}
$$

The $D G I^{\theta}$ is the most general quantitative aproximation of the international integra-

\footnotetext{
${ }^{8}$ We admit the way to combine both partial indices $\left(D O^{\theta}\right.$ and $\left.D B C^{\theta}\right)$ is somewhat ad hoc. However, our main point is that it is important for trade integration to consider both effects, regardless of the way they are combined.
} 
tion of economies, as it considers the degree of openness as well as the distribution and size of the flows between economies.

\section{Data presentation}

For computing the different indicators presented in the previous section we need information on trade flows, output (measured using GDP) and distances, both between countries (external) and within countries (internal). All these variables are drawn from the data set Comptes Harmonisés sur les Echanges et l'Economie Mondiale, or Harmonised Accounts on Trade and The World Economy (CHELEM), a database which is available at URL http://www.cepii.fr/anglaisgraph/bdd/chelem.htm (data compiled by CEPII, Paris). Although this database is perhaps not the most popular in trade studies, its use is convenient because it includes different types of information for most of the countries in the database, covering a long time period. Apart from the variables needed to compute the indicators presented in Section 2, it also contains other relevant information such as population, specialization (in exports), data on services, etc.

Our data sample corresponds to 59 countries accounting for $96.7 \%$ of world output and $86.5 \%$ of international trade in 2005 . Table 1 shows the list of countries considered, which includes all large economies. Both developed and developing countries are also included, and the geographic origin of the different countries is heterogeneous- there are countries from all continents. The variable selected to measure the flows between countries is the volume of exports. The computations for indicators based on imports do not alter the average general results, although they may differ for some specific countries. ${ }^{9}$

Our sample period stretches from 1967 to 2005, covering entirely what some authors have labeled the second wave of globalization (Maddison, 2001; O'Rourke and Williamson, 2002). Using information for such a long time period (39 years) comes at a price, namely, the fact that some countries have to be excluded. Should we constrain the analysis to a shorter time period, the number of countries included in the study could increase. This trade-off between the number of countries in the sample and the length of the analyzed period can be partly overcome by choosing a sufficiently repre-

\footnotetext{
${ }^{9}$ These results are not reported due to space limitations (it would basically double the space devoted to the results), but are available from the authors upon request.
} 
sentative sample-in terms of both world output and trade-which is what we finally did. Moreover, as indicated by Redding and Schott (2003), in some circumstances it may be problematic to include a high number of countries because results could be driven by small countries that trade very little with the rest of the world. However, we admit that another alternative-i.e., choosing more countries and less years-would also yield relevant results.

The same institution that provides data on trade flows and GDP also supplies other relevant pieces of required information crucial for this study, such as distance. Two types of distances are considered. The distance from country $i$ to country $j$ (external distance, $d_{i j}$ ) is measured by the distance (great circle distance) between the main city of the country which, in most cases, is the capital of the country. ${ }^{10}$ The data set also provides information on internal or intra-national distances $\left(d_{i i}\right)$. Those employed here are based on areas, and they are necessary for constructing the distance-corrected indices. We measure it via an often used measure of average distance between producers and consumers in a country (Head and Mayer, 2002):

$$
d_{i i}=.67 \sqrt{\operatorname{area} / \pi}
$$

where area is country $i^{\prime}$ s area in square $\mathrm{km}$. However, as indicated by Head and Mayer (2002), there has been little consensus on the appropriate measure of internal

\footnotetext{
${ }^{10}$ In some cases such as France the same city accomplishes simultaneously the criteria of being the capital, the largest city and a centrally located large city. However, there are a number of cases in our sample for which the economic center differs from the capital: South Africa (The Cap), Germany (Essen), Australia (Sydney), Brazil (São Paulo), Canada (Toronto), United States (New York, although in practice most studies use Chicago) and Turkey (Istanbul).
} 
distance. ${ }^{11,12}$ Ideally, an accurate measure of internal distance should include information on the key points of entry of trade into the country, the quality of the infrastructure, or the modes of transport. Unfortunately, such information is not available for all countries in our sample.

Using data on internal distances opens an intriguing and relatively unexplored debate, since the number of studies venturing into how intra-national distances affect trade is much lower than the number of studies focusing on external distances only. Yet we must admit that a specific analysis of how differently inter-national and intra-national distances affect trade is an issue that goes beyond the aims of this paper where we address this issue only partly. As indicated in section 2, defining distance-corrected shares of country $i$ 's GDP as $r_{i}=\left(Y_{i} / d_{i i}^{\theta}\right) / \sum_{j \in N}\left(Y_{j} / d_{i j}^{\theta}\right)$ has several advantages-i.e., we factor in the iceberg effect, and the results do not depend on the units of measurement.

The distance-corrected relative weights, $r_{i}$ (which are also available upon request), as expected, differ from those for distance-uncorrected relative weights, $a_{i}$ for all countries, but the magnitude of the discrepancies varies ostensibly across countries. Given the way to construct the $r_{i}$ parameter, it will depend not only on how far countries are located from their trade partners but also on the magnitude of their internal distances obtained via Equation (9). For instance, by 2005 the U.S. share of world (sample) GDP ( $a_{\mathrm{USA}}=$

\footnotetext{
${ }^{11}$ Although the measure proposed in Equation (9) lies within the group of area-based measures, the early papers in the literature employed fractions of distances to the centers of neighbor countries (Wei, 1996; Wolf, 2000), which were criticized by Nitsch (2000b), among others, soon afterwards. Apart from our area-based measure, there are other interesting proposals within this family. For instance, Nitsch (2000b) and Leamer (1997) use the radius of a hypothetical disk (i.e., $\sqrt{\operatorname{area} / \pi}$ ), Redding and Venables (2004) link intra-country transport costs to the area of the country by using the formula $d_{i i}=.33 \sqrt{\mathrm{area} / \pi}$. Years before Keeble et al. (1988) relied on the same formula- whereas Helliwell and Verdier (2001) consider internal distances of cities

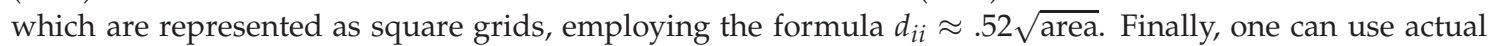
data on the spatial distribution of economic activity within nations rather than working with geometric approximations, yielding sub-unit based weighted averages. Following Head and Mayer (2002), one may conclude that a desirable measure of internal distance might be calculated either directly using sub-national data on the geographic distribution of activity, or by making various simplifying assumptions. According to the comparison of measures performed by Nitsch (2000a), the area-based approximations (such as the one we employ) are fine indicators of the averages of sub-national distances, which makes our choice reasonable.

${ }^{12}$ Regarding the use of the 0.67 constant, the intra-national distances we use are derived from the following hypotheses (Head and Mayer, 2002): (i) the economic geography of each country is approximated with a disk in which the production concentrates at the center, and (ii) consumers are randomly distributed throughout the rest of the area. Under these assumptions, the average distance between a producer and a consumer is given by $d_{i i}=\int_{0}^{R} r f(r) d r$, where $R$ is the radius of the disk, and $f(r)$ is the density of the consumers at any given distance $r$. If the area of the country is $A$, then we obtain $R$ equal to $\sqrt{A / \pi}$. The uniform density distribution corresponds to $f(r)=2 r / R^{2}$. Then, $d_{i i}=\int_{0}^{R} 2 r^{2} / R^{2} d r=(2 / 3) r^{3} /\left.R^{2}\right|_{0} ^{R}=$ $(2 / 3) R=(2 / 3) \sqrt{A / \pi}$. In other words, in the hypothetical country, a representative consumer is located at a distance of 0.67 from the center of the disk.
} 
$29.01 \%$ ) was almost three times that of Japan $\left(a_{\text {Japan }}=10.67 \%\right)$. However, the distancecorrected shares of world GDP are much closer $\left(r_{\mathrm{USA}}=63.99 \%\right.$ and $\left.r_{\text {Japan }}=78.04 \%\right)$, since the effects of $d_{i j}$ and $d_{i i}$ on $r_{i}$ are opposite, and the intra-national distances for the U.S. are higher than those for Japan.

Our analysis is restricted to trade in goods only. Since specialization patterns vary across countries, there is a bias for our indices which will affect countries differently. However, extending the analysis to account for trade in services is not possible, since there are no services equivalent to the matrix of trade in goods between country pairs.

\section{Results}

Results for the degree of global openness $\left(D G O^{\theta=0}\right.$ and $\left.D G O^{\theta=1}\right)$ correspond to the evolution of the weighted mean in both upper panels of Figure 1 (Figure 1.a). They are also reported in Table 2. The values are reported explicitly given our specific interest in measuring trade integration. On average, the degree of openness has more than doubled for $D G O^{\theta=0}$ and almost tripled for $D G O^{\theta=1}$ from 1967 to 2005 . It would suggest how open the world economy is, and it is apparent that if we acknowledge that distance matters (including it explicitly to construct the indicators), the level of openness is higher. In both instances, however, the degree of openness advances at a similar pace: in the economy where distance is irrelevant $\left(D G O^{\theta=0}\right)$ the increase is from $8.03 \%$ to $20.84 \%$, and when location matters $\left(D G O^{\theta=1}\right)$, the increase is higher (from $12.13 \%$ to $32.27 \%$ ). However, the analysis by subperiods discloses additional results: for $D G O^{\theta=0}$, the highest increase took place after 1986, whereas for $D G O^{\theta=1}$ it occurred before. This finding may be explained by the role of countries such as Japan, which is big in GDP terms (therefore its behavior affects the evolution of $D G O$ ), which is distant, and whose $D O_{i}$ increased sharply before 1986.

Figure 1.b displays results for the degree of balanced connection under the two scenarios $\left(D G B C^{\theta=0}, D G B C^{\theta=1}\right)$. The most apparent feature is that they are much closer to the economies' theoretical full potential $(100 \%)$ for connection than $D O^{\theta}$, particularly when distance matters $(\theta=1)$. However, the average increases have been more modest than in the degree of openness case, also because initial levels were already high. These tendencies are common under geographic neutrality $(\theta=0)$ and $\theta=1$, 
although the increase has been even more modest in this last case. The values corresponding to the degree of global balanced connection DGBC are also reported in Table 2. In contrast to the result obtained for the degree of openness, the wealthier countries (as indicated by the weighted mean) are those with the highest degrees of balanced connection. These values peaked before the 1990s. The most interesting results, however, emerge when dropping the physical irrelevance assumption and distance enters the analysis, for which all countries lie above $D B C=70 \%$. Therefore, once the downward impact of distance on the volume of trade is controlled for, countries export more "proportionally" to the size of their trading partners. In other words, if as found and predicted by gravity models distance matters, and its importance does not seem to diminish sharply over time despite the decline in transportation costs, the current level of balanced connections would already be high. However, the balance would be lessened from the perspective of a global village, where the role of remoteness disappears.

The degree of integration results from combining the effects of the DGO and the $D G B C$. The evolution of the basic summary statistics is reported in Figure 1.c. The relevant message is not only that it indicates the level of international trade integration achieved by each country but, more importantly, that it indicates how far each country is from its theoretical full potential for integration. Although there are some exceptions to the rule, countries are generally more integrated when controlling for distance, when their degree of integration decreases. The interpretation of these particular cases is straightforward: these are countries whose exports suffer from a "distance bias", since the major trading partners for these countries are remotely located-i.e., in the case of distance being relevant, they should export more to their geographic neighbors. Therefore, it is obvious that this type of result only arises for countries sharing several characteristics, among which we might consider the fact of being surrounded by developing countries (e.g., Algeria, Gabon, Nigeria, Pakistan and, to a lesser extent, Chile) or being highly exporting countries whose trading partners are physically distant (China, Malaysia and Singapore). However, there are also political reasons involved. If countries are members of a regional trade agreement (usually with physically-close nations), there will exist a bias to trade more with other members. In contrast, in some particular cases there is bias to trade less with neighbors: for historical and political reasons, there are countries which trade relatively little with one another in spite of being physically close. 
In our sample, some examples would include Japan-South Korea, or India-Pakistan. In addition, for many of our sample years, former European communist countries could barely trade with their Western neighbors.

The specific values for the degree of global integration (DGI) are reported in Table 2. The general assessment of the level of world integration (DGI) as of 2005 is that, in the case of distance still being relevant, we are already halfway to the theoretical full potential for global trade integration. However, from the perspective of the global village, where distance becomes an irrelevancy, the process is still in a previous stage, since the degree of global integration decreases sharply (from 50.96\% to 35.48\%). Yet the range of possible particular behaviors is broad: the standard deviation (not reported) has increased sharply (although the coefficient of variation has declined due to the growing average), and probability mass becomes increasingly spread, suggesting that some countries are quite close to the unity, yet many others are still far-although the prevailing picture is that trade integration is advancing.

\section{Analyzing the determinants of the distance trade bias}

Figure 2 provides a preliminary view on the changing role of distance over the 19672005 period. It shows the evolution of the $D G O^{\theta=1} / D G O^{\theta=0}, D G B C^{\theta=1} / D G B C^{\theta=0}$ and $D G I^{\theta=1} / D G I^{\theta=0}$ ratios, which is disparate. Whereas all three indicators departed from similar values (ranging in the $] 1.4,1.6\left[\right.$ interval), the $D G O^{\theta=1} / D G O^{\theta=0}$ increased until the mid nineties, and then decreased to virtually the initial value. The evolution of the $D G B C^{\theta=1} / D G B C^{\theta=0}$ has been the opposite, but much more attenuated. $D G I^{\theta=1} / D G I^{\theta=0}$ shows their combined effect.

Given the length of the period (39 years) and the heterogeneity of countries making up our sample, the reasons explaining the behavior of all three indices will be multiple, complex and, as we have been pointing out from the introduction, country-specific (Jones, 1992). Some particular countries such as South Africa, China or the European countries belonging to the former Eastern Bloc, to name but a few, have gone through significant political change, which in most cases has affected trade significantly.

However, some of the trends in Figure 2 could be partly explained away by relevant events which have intensified over the last few years. It is worth noting the fact that 
the tendencies for $D O$ and $D B C$ have evolved in opposite directions. Considering that an indicator of 1 implies that distance is irrelevant, according to the $D O$ its importance increased until the mid nineties. This could be related to the fact that over the last fifty years an increasing number of remote countries have started to trade more intensively. Since the mid nineties, when regional trade agreements have bloomed the tendencies have reversed. This could be related to the fact that our degree of openness partly reflects trade creation (countries adhering to regional trade agreements trade more) whereas the degree of balanced connection partly reflects trade diversion (if members of a given RTA trade more among themselves, their $D B C$ should probably decrease).${ }^{13}$ A proper investigation into the determinants of these discrepancies requires less speculative approach.

We consider that large discrepancies among distance-corrected and uncorrected values of our trade integration indicators constitute an equivalent to the persistence of the distance coefficient in gravity equations. The basic version of these models considers that trade between country $i$ and a number of partner countries $j, T_{i j}$, is a function of GDP of both country $i\left(Y_{i}\right)$ and country $j\left(Y_{j}\right)$, and geographic distance between the two countries, DIST $T_{i j}$. Therefore, the following model and the like are generally estimated,

$$
\ln T_{i j}=\beta_{0}+\beta_{1} \ln \left(D I S T_{i j}\right)+\beta_{2} \ln \left(Y_{i}\right)+\beta_{3} \ln \left(Y_{j}\right)+\varepsilon_{i j}
$$

where $\varepsilon_{i j}$ is the error term. The right-hand side in Equation (10) is usually enlarged so as to control for variables such as common language, land border, colonizer, the condition of being landlocked, the existence of a free trade area, and sometimes a common currency.

As it has been documented throughout the paper, discrepancies among distancecorrected and distance-uncorrected trade integration indicators vary a great deal both on average but, most importantly, across countries. This would imply that the effect of distance is not homogeneous across countries and therefore the estimated $\beta_{1}$ 's in Equation (10) might be country-dependent implying that, when dealing with the issue as to whether "distance has died" or not, we should temper the statements by also adding that distance is still significant on average. Some authors have indeed pointed out that

\footnotetext{
${ }^{13}$ However, the line of reasoning is intricate. As indicated by Wonnacott (1996), regional free trade agreements might be better than what is usually predicted when they are formed or expand, and worse when they multiply.
} 
nonlinearity may be the problem. For instance, Coe et al. (2007) estimate a gravity equation with an additive error term and find that there was some decline in the distance coefficient. Other authors also point out this varying effect across countries, by considering that geographic distance is a proxy for unfamiliarity and that exporters in high uncertainty-aversion countries are more sensitive to informational ambiguity (Huang, 2007). However, there have been few initiatives so far to measure how relevant the distance effect is for each specific country. Following the ideas presented in the introduction, some authors warn explicitly about the dangers of "attempting to apply generalizations about human action gained from aggregate data, which summarize the overall acts of a large number of heterogeneous people, to make inferences about how individuals act" (Sheppard, 1984).

Table 3 illustrates the severity of this problem. It shows the discrepancies between both $D B C^{\theta=0}$ and $D B C^{\theta=1}$ for some particular countries. The left panel lists countries for which distance matters, as revealed by large discrepancies between distance-corrected $\left(D B C^{\theta=1}\right)$ and uncorrected $\left(D B C^{\theta=0}\right)$ indices. For most countries in this list the values of $D B C$ are almost doubled when controlling for the distance separating them from their trading partners. This is an interesting illustration of the iceberg effect. The relatively low values found for the European Union countries in the list indicate they trade less proportionally than what frictionless trade would predict. Should they trade more proportionally to the economic size of their trading partners, the indicator would increase. The range of possible explanations will be of course much wider, and probably more complex. However, Table 3 stresses clearly that the magnitude and significance of the distance parameter in gravity equations should be assessed with care, and it is perhaps convenient to evaluate it within the setting of Casetti's (1972) expansion method.

Controlling for distance $(\theta=1)$ implies assuming that "only a fraction of ice exported reaches its destination as unmelted ice", as stated earlier. This is equivalent to assuming that trading partners in distant locations become smaller when bringing them closer to the exporting country. In the case of the European Union countries, large economies such as Japan or the U.S. would become much smaller, implying that, according to geographic neutral trade, we can expect that European countries trade less with them-which is precisely the case. Once distance is removed via the iceberg effect, Japan and the U.S. are not large countries anymore from a European geographical 
position and therefore the $D B C$ of most European countries increases sharply.

In contrast, the right panel in Table 3 lists some countries for which distance is not as relevant, as shown by low discrepancies between $D B C_{i}^{\theta=0}$ and $D B C_{i}^{\theta=1}$. This indicates that the countries in the list trade according to the predictions of geographic neutral trade. In some cases the values found for $D B C$ when controlling for distance are even lower than those found under frictionless trade. This indicates that these countries (Chile, China, India, Nigeria) trade "too much" (according to the geographic neutrality standard) with distant countries, or not enough with their neighbors.

We explore some covariates which could contribute to explaining this varying role of distance for the different countries in the sample. However, the list of covariates is not exhaustive. We are especially constrained by the fact that, whereas gravity equations try to explain variability in bilateral trade flows, for which they include distance regressors, in our case distance is endogenous. This constrains both the number an nature of the variables that can be included as regressors. Some of them are variables that capture the existence of regional trade agreements. Although there is a wide range of different forms of integration arrangements, including free trade areas, customs unions, and preferential trading areas, we use RTAs as a generic descriptor following the proposals by Greenaway and Milner (2002). Some authors consider regionalism might enhance shortdistance trade and therefore be the most obvious explanation for the non-declining role of distance (Berthelon and Freund, 2008), whereas technological improvements might favor long-distance trade. Indeed, Hummels (1999) finds that containerization reduced the relative cost of distance. As indicated by Alesina and Spolaore (1997), trade blocs (which they label as political integration) harm economic integration, accounting for why economic integration is usually found to be low for members of free trade agreements.

In spite of being currently more, we consider only the most important RTAs: namely, the European Union, NAFTA, MERCOSUR, and ASEAN. These are major RTAs in Europe, America and Asia, although a relatively small but growing number apply to the trade of developing countries. Most applications of the gravity model have also searched for evidence of actual or potential effects by adding dummy variables for membership of a particular RTA. We add a related variable whose importance is not always considered by the literature: namely, the number of years each country has been member of its 
corresponding RTA. By including this dummy variable, we will be able to test whether there is an identifiable RTA effect, and to recognize those variables on which the RTAs' dummies may have stronger effects. In addition, it constitutes a good proxy for the depth of the commercial links between the different trading partners.

We also include in our regressions the GDP of each country-recall that since we have constructed country-specific indicators we do not use bilateral information. Gravity equations generally find that the economic size of each partner is a significant explanatory variable for the trade volumes between them. In our specific setting, the equivalent result would be that country i's GDP is significant. Not only has the general literature on gravity equations documented this issue but also Alesina and Spolaore (1997) among others, who argue that bigger domestic markets constitute important incentives for large countries to trade less. As also indicated by Brun et al. (2005), trade tends to constitute a smaller percentage of GDP for larger countries. Some studies also include GDP per capita. Although the impact is not entirely coincidental with that of GDP, due to the high correlation between GDP and GDP per capita results tend to be similar. However, given this high correlation between both covariates, it will not be possible to include them in the models simultaneously.

We include in our regressions some of each country's specialization patterns. There is a vast literature on the effects of specialization on trade (see, for instance Redding, 2002; Redding and Schott, 2003; Schott, 2004). The changing composition of trade has been found to be an explanation for the stability over time of the estimated distance coefficients in gravity equations (Coe et al., 2002). As indicated by Berthelon and Freund (2008), the increase in the importance of distance estimated using aggregate gravity regressions could be due to an increase in the share of trade accounted by distancesensitive products. Indeed, these authors find that distance has become more important for some industries. Thus, this information is crucial for explaining whether the effect of distance is still there or not, since there are some products which will be traded intensely regardless of where trading partners are located. In addition, in many cases the countries surrounding the main producers of these products have similar specializations, which makes the role of distance even more prominent.

One of the most widely accepted indicators of a country's trade specialization is the Balassa (1965) "Revealed Comparative Advantage" (RCA) index (see further discussion 
in, for instance Leamer and Levinsohn, 1995), defined as:

$$
R C A_{i j}=\frac{X_{i j} / \sum_{j} X_{i j}}{\sum_{i} X_{i j} / \sum_{i} \sum_{j} X_{i j}}
$$

where the ratio in the numerator is the share of country $j$ in sector $i$ world exports, whereas the ratio in the denominator represents the same share for total merchandise exports. Those cases where the index takes values less than 1 indicate these are sectors in which a country is relatively less specialized with respect to the world economy. Values of the index greater than 1 denote sectors in which a country is relatively more specialized with respect to the world economy. However, although this index has the advantage of being a comprehensive indicator of the concept of specialization, there are no clear theoretical foundations for this measure (Brasili et al., 2000).

Although it was possible to consider a sectoral classification with the highest level of detail, our data covers 10 sectors, which coincides (in terms of number of sectors) with previous studies such as Chen et al. (2009). We consider this is a reasonable balance, since reducing the number of sectors would imply aggregating some relevant information. These sectors include construction, basic metals, textiles, wood paper, metal products, chemicals, mining, energy, agriculture, and food products. There is also a miscellaneous category for the remainder.

We also include an indicator of remoteness in per capita income, following some of the ideas and proposals by Nitsch (2000b). If we define the bilateral distance in GDP between two countries $i$ and $j$ as $d r_{i j}=\left|Y_{i}-Y_{j}\right|$, where $Y$ represents the (log of) GDP for each country, then the indicator of remoteness in per capita income for country $i, R_{i}$, can be defined as:

$$
R_{i}=\frac{1}{\sum_{k \in N} N_{k} / d r_{i k}}
$$

where $N_{k}$ represents the population of country $k$. Although the expected impact of $R_{i}$ on trade will be involved (it will probably be different for $D O$ and $D B C$ ), one may hypothesize that poor countries (which are remote in per capita income) will be less affected by physical distance, since big markets are distant.

Therefore we estimate two basic models, since we analyze the impact of the selected covariates on two of our three main indicators (openness and connection). Although the analysis could also be extended to the degree of integration, the fact that it combines 
two indicators with different economic implications makes interpretation overly intricate. Confining the analysis to the impact on the two components of trade integration facilitates the readability of the paper. We also analyze some of their variants, by combining the set of determinants in different ways. If we refer to the ratio $D^{\theta=1} / D^{\theta=0}$ as the general expression for the three ratios $D O^{\theta=1} / D O^{\theta=0}$ and $D B C^{\theta=1} / D B C^{\theta=0}$, then the model to be estimated presents the following general form:

$$
\begin{aligned}
D_{i t}^{\theta=1} / D_{i t}^{\theta=0}=\alpha_{i}+\beta_{1} G D P_{i t}+\beta_{2} R E M O T E \_G D P_{i t}+ & \\
& +\gamma^{\prime} \sum_{j} R C A_{i j t}+\beta_{3} Y R T A_{i t}+\beta_{4} R T A_{i t}+\varepsilon_{i t}
\end{aligned}
$$

where $G D P_{i t}$ will refer either to the logarithm of country $i$ GDP, or per capita GDP (which will not be considered simultaneously), in year $t, R E M O T E_{-} G D P_{i t}$ is the remoteness in per capita GDP of country $i, R C A_{i j t}$ is the Balassa Revealed Comparative Advantage index for country $i$, sector $j$ and year $t, Y R T A_{i t}$ is the number of years country $i$ is member of its corresponding RTA (if this applies) in year $t$, and $R T A_{i t}$ is a dummy variable which takes the value of 1 for countries members of the RTA considered. We include the $t$ subscript so as to account for the time dimension of the role of distance. As indicated by Brun et al. (2005), there are potential problems when using cross-section to estimate Equation (13) and the like. Some of these problems are related to the heterogeneity not captured by dummy variables, which could cause biased estimates. Others are related to the omitted-variables bias to which typical ordinary least squares estimates may be prone to. Therefore we estimate Equation (13) using cross-section fixed effects, which are included in the $\alpha_{i}$ parameter, so that the unobservable heterogeneity is partly addressed.

However, the impact of the different RTAs on distance might be involved, since RTAs differ in many respects. For instance, in Europe integration goes beyond merely establishing a free trade area, since both capital and labor can move freely and there is an even more ambitious initiative for political integration with the European Constitution. This is a big contrast with the features of NAFTA, where free flow of labor across member states is not possible. Thus, we consider it relevant to analyze separately how each particular RTA might affect distance by considering four simpler versions of Equation (13) in which the RTA variable is substituted sequentially by EU, NAFTA, ASEAN, and 
MERCOSUR variables.

Table 4 shows estimation results for Equation (13) in which the dependent variable is $D O^{\theta=1} / D O^{\theta=0}$, whereas Table 5 reports analogous information for $D B C^{\theta=1} / D B C^{\theta=0}$. As indicated earlier, we estimate Equation (13) using cross-section fixed effects. Our results report robust covariance matrix estimation. In the context of panel data, the most general version of White's (1980) heteroskedasticity-consistent covariance matrix proves consistent against serial correlation as well. However, in the fixed effects case the original White estimator turns out to be inconsistent in some particular cases (for instance, for fixed $T$ as $n$ grows), so it may be more advisable to use the Arellano (1987) version, which allows a fully general structure with respect to both heteroskedasticity and serial correlation (Stock and Watson, 2008). ${ }^{14}$

Table 4 indicates that the effect of GDP on distance-as measured by larger discrepancies among $D O^{\theta=1}$ and $D O^{\theta=0}$-is positive. This implies that for large economies openness is strongly affected by distance, as heavily documented in the literature (home market effect hypothesis). This coefficient is positive and significant at the $1 \%$ significant level throughout. Both the sign and the significance of the coefficients hold when including GDP per capita (GDP_PC) instead of GDP. As indicated earlier, one could $a$ priori forecast this result, given the usually high correlation between GDP and GDP per capita-although for our data correlation was not particularly high (0.416). Regarding the variable reflecting remoteness in GDP per capita, although its sign is negative (as one could also expect), it is not significant for any of the specified models. In contrast, the variable REMOTE_GDP has a negative impact, although it is not significant-recall that it measures remoteness in per capita income, not in distance.

Assessing the impact of the specialization variables is intricate. The literature has acknowledged how complex it may be using different approaches. For instance, Schott (2004) indicates that "thinking about international specialization must shift away from industries (e.g., apparel vs. machinery) and toward varieties within industries (e.g., analog vs. high-definition television)". The evidence he finds in his paper would suggest that conventional tests of trade theory which use industry-level data present some difficulties because much of the endowment-driven specialization takes place at a level

\footnotetext{
14 As indicated by Jones and Bullen (1994), autocorrelation is a key feature of any geographic analysis. Since standard statistical techniques assume that data are independent, it is important to report robust standard errors which are "adjusted" to take account of the autocorrelation (Jones and Bullen, 1994, p.269).
} 
that until relatively recently was not available. In our particular setting, the share of total energy in each country's exports (ENERGY) has a negative and significant effect throughout on the discrepancies between $D O^{\theta=1}$ and $D O^{\theta=0}$. This result is reasonable, implying that high energy-exporting countries are those whose openness is less affected by distance (their volume of exports is not determined by the location of their trading partners), whereas the opposite pattern holds for low energy-exporting countries. This effect does not hold for other specializations such as AGRICULTURE and FOOD_PRODUCTS, whose sign is positive throughout-although not always significant.

The variables related to free trade areas must be commented on jointly, given there are non-negligible interactions among them. Countries with the highest $D O^{\theta=1} / D O^{\theta=0}$ ratios are those more affected by distance when evaluating their openness. However, as indicated by the columns in Table 4 corresponding to models 2 and 4 , being member of a regional trade agreement ( $R T A$ variable) has a negative effect on $D O^{\theta=1} / D O^{\theta=0}$ or, equivalently, countries adhered to the RTAs considered in this study are less affected by distance in their degrees of openness. This sign is dominated by the negative and significant coefficient (at the 1\% level) found for EU (models 1 and 3), and constitutes a plausible result, given that many EU countries are quite open-especially to their RTA partners. Yet not all RTAs contribute the same way, since only EU shows significant relationships throughout. In the case of ASEAN and NAFTA the relationships are significant, but significance is not reached throughout-especially for ASEAN. For $M E R C O S U R$ it is never significant. Therefore, one may easily infer that it is relevant to consider the different trade agreements separately due to their varying effects on the dependent variable. Finally, we also analyze the "depth" of the free trade agreements considered, as measured by $Y R T A$, whose sign is negative and significant (1\%) throughout. That is, the longer the durability of the RTA, the less relevant the effect of distance-as revealed by lower discrepancies between $D O^{\theta=1}$ and $D O^{\theta=0}$. Therefore, it seems that once a particular country becomes member of an RTA, the effect of distance shortly becomes as relevant as for older members.

We now turn to the analysis of the impact of each covariate on $D B C^{\theta=1} / D B C^{\theta=0}$. In general, as revealed by Table 5, results vary remarkably with respect to those in Table 4 , constituting further evidence on how different the economic meanings of the degree 
of openness and the degree of balanced connection are. Indeed, in many instances the sign of the relationships is reversed, suggesting that $D O$ and $D B C$ are but different ways through which economies become more trade integrated.

The impact of GDP on $D B C^{\theta=1} / D B C^{\theta=0}$ is negative and significant throughout. Countries for which this discrepancy is high are those whose trading partners (both in terms of number and proportionality) are close-i.e., once we control for distance, the $D B C$ increases sharply. This means that large countries, in terms of GDP, export more proportionally both in terms of distance and size of their trading partners. This finding might constitute a certain surprise for some large countries like the US, whose exports to Canada are higher than those to distant and large countries such as Germany. However, for some other large economies, not only Germany itself but also Japan, China or India, exports are more geographically neutral-these countries export regardless of the location of the importing countries, and in proportion to their relative sizes. The impact of GDP_PC is similar, as one might a priori expect because of the high correlation with GDP, although significance deteriorates slightly for Model 4. Regarding the impact of REMOTE_GDP, it is also negative yet not-significant throughout (only at the $10 \%$ significance level, for models 1 and 3), analogously to what we found for the degree of openness.

The specialization variables are not entirely coincidental either when comparing Table 4 and Table 5, and some results are intricate. However, in general the sign of the coefficient is what one might a priori expect. For instance, the coefficient of AGRICULTURE in Table 5 is positive and significant at the $1 \%$ level throughout, implying that for those countries more specialized in agriculture (according to the $R C A$ index of specialization) distance is quite relevant- the $D B C$ index rises sharply when comparing $D B C^{\theta=0}$ and $D B C^{\theta=1}$. Therefore, given their specialization in agricultural products (generally perishable, and object of preferential trade agreements), these economies are used to exporting to their neighbors, and consequently are not affected by geographically-neutral trade.

The variables related to free trade area membership also show dissimilar patterns when comparing results in Table 4 and Table 5. The general effect (RTA) is not reversed, but it loses significance entirely. However, this outcome is the combination of opposed effects. On the one hand, analogously to what was found for DO (Table 4), the effect of ASEAN is negative and significant-but now the significance is much higher 
(1\%). In contrast, all EU, MERCOSUR, and NAFTA are not only significant but, most importantly, the sign of the coefficient is positive. Again, the effect of free trade area membership varies across the different trade agreements. In the particular case of $E U$, MERCOSUR, and NAFTA the positive effect indicates that the architecture of their member's trade relations is positively biased towards other members of the agreement. However, the effect is the opposite in the case of ASEAN, and the bias exists towards non-members of the free trade agreement.

At this point, it is important to reconcile the results found for DO (Table 4) and $D B C$ (Table 5), given the disparities found for some of the covariates. The origin of the disparities is derived from the fact that, as stated throughout the paper, they measure different aspects of international trade integration, which does not advance only via trade openness but also via a balanced structure of trade relations. In this setting, the effect of distance is neither homogeneous across countries nor across indicators.

The presence of spacial patterns in the residuals of any of the estimated models could suggest that it would be beneficial to partially modify them to account for spatial autocorrelation. While this is an interesting initiative, we think it goes beyond the aim of our particular contribution, deserving a specific investigation.

\section{Conclusions}

Since the emergence of the study by Leamer and Levinsohn (1995), many research initiatives have debated the apparent inconsistency of declining trade-related costs (at least for some products) and a highly negative and significant coefficient of distance in gravity equations, which does not diminish over time. Some authors (Anderson and van Wincoop, 2004) claim such inconsistency might not be real when realizing that technology growth in shipping advanced more slowly than the rest of the economy during the twentieth century and, consequently, transport costs might have increased as a fraction of average marginal production costs. However, this interpretation has not been widely accepted, and there is a non-negligible body of the literature that has explored different explanations for this inconsistency (since with globalization one would expect the distance coefficient to decline over time).

We provide yet another explanation for this "missing globalization puzzle", as coined 
by Coe et al. (2002), also labeled as "the conservation of distance in international trade" (Berthelon and Freund, 2008). Much of this evidence is framed within the context of gravity equations, as indicated by the meta-analysis by Disdier and Head (2008). We adopt a different stance, basing our explanation on the construction of two sets of indicators on economic integration, one of them controlling for distance, the other being distance-uncorrected. These indicators are based on the geographical neutrality concept by Krugman (1996), and the Standard of Perfect International Integration by Frankel (2000).

Our methods echo the ideas of Casetti $(1972,1991)$ and followers of the expansion method. Since his early studies were published, several geographers have paid considerable attention to contextual quantitative models, which moved away from models that "denied" geography (Foster, 1991), allowing relationships to vary according to context. Some geographers have dealt explicitly with the issue at stake. As indicated by Eldridge and Jones (1991) "few concepts are more central to the discipline of geography than distance decay", but "most research designs implicitly assume that the friction of distance has-within any single model-an unvarying effect across the spatial units from which data are derived and estimates made". We attempt to measure explicitly how, in the context of trade, this effect varies from country to country.

Results indicate that the discrepancies found among both sets of indicators (distancecorrected and distance-uncorrected) have a non-negligible dynamic component, since the importance of distance increased until the mid-nineties, but has returned to levels of 30 years ago. This implies that, according to our indicators, the role of distance, on average, is still there. However, a more interesting result is that discrepancies among distance-corrected and distance-uncorrected indicators differ a great deal across countries. That is, the effect of distance is there, but the impact on each country's level of integration is varying and, therefore, it might be hazardous to attempt to identify consistent empirical regularities that could ultimately lead to the formulation of "universal spatial laws". As indicated by Eldridge and Jones (1991), it may be more appropriate to approach the conundrum we are dealing with (i.e., the conservation of distance in international trade) via the expansion method, which "rejects the notion that models should perform in a similar fashion across varied contexts" (Eldridge and Jones, 1991, p.510). 
A mere cursory look at the different levels of integration for the different countries in our sample will promptly suggest that the heterogeneity found for the effect of distance might not be entirely random. Accordingly, we explore some factors that might explain these discrepancies, finding that GDP, specialization and, very remarkably, regional trade agreements contribute to explaining the heterogeneity. Yet for some of the explanatory variables the relationship is rather involved, since RTA membership affects distance depending on each particular RTA. 


\section{References}

Alesina, A. and Spolaore, E. (1997). On the number and size of nations. Quarterly Journal of Economics, 112:1027-56.

Anderson, J. E. (1979). A theoretical foundation for the gravity equation. American Economic Review, 69:106-116.

Anderson, J. E. and van Wincoop, E. (2003). Gravity with gravitas: A solution to the border puzzle. The American Economic Review, 93(1):170-192.

Anderson, J. E. and van Wincoop, E. (2004). Trade costs. Journal of Economic Literature, 42(3):691751.

Andresen, M. A. (2010). Geographies of international trade: Theory, borders, and regions. Geography Compass, 4(2):94-105.

Arellano, M. (1987). Computing robust standard errors for within-groups estimators. Oxford bulletin of Economics and Statistics, 49(4):431.

Arribas, I., Pérez, F., and Tortosa-Ausina, E. (2009). Measuring globalization of international trade: Theory and evidence. World Development, 37(1):127-145.

Balassa, B. (1965). Trade liberalisation and "revealed" comparative advantage. The Manchester School, 33(2):99-123.

Berthelon, M. and Freund, C. (2008). On the conservation of distance in international trade. Journal of International Economics, 75:310-320.

Boulhol, H. and de Serres, A. (2010). Have developed countries escaped the curse of distance? Journal of Economic Geography, 10:113-139.

Brakman, S. and van Marrewijk, C. (2008). It's a big world after all: On the economic impact of location and distance. Cambridge Journal of Regions, Economy and Society, 1(3):411-437.

Brasili, A., Epifani, P., and Helg, R. (2000). On the dynamics of trade patterns. De Economist, 148(2):233-258.

Brun, J., Carrere, C., Gillaumont, P., and de Melo, J. (2005). Has distance died? Evidence from a panel gravity model. World Bank Economic Review, 19:99-120.

Cairncross, F. (1997). The death of distance: How the communications revolution will change our lives. Harvard Business Press, Massachusetts. 
Carrere, C. and Schiff, M. (2005). On the geography of trade: distance is alive and well. Revue Economique, 56:1249-1274.

Casetti, E. (1972). Generating models by the expansion method: applications to geographical research. Geographical Analysis, 4(1):81-91.

Casetti, E. (1991). The investigation of parameter drift by expanded regressions: generalities, and a 'family planning' example. Environment and Planning A, 23(7):1045-1061.

Castells, M. (1998). End of Millennium. Blackwell Publishers, Malden, Massachusetts.

Chen, N., Imbs, J., and Scott, A. (2009). The dynamics of trade and competition. Journal of International Economics, 77(1):50-62.

Christopherson, S., Garretsen, H., and Martin, R. (2008). The world is not flat: putting globalization in its place. Cambridge Journal of Regions, Economy and Society, 1(3):343-349.

Coe, D. T., Subramanian, A., and Tamirisa, N. T. (2007). The missing globalization puzzle: Evidence of the declining importance of distance. IMF Staff Papers, 54(1):34-58.

Coe, D. T., Subramanian, A., Tamirisa, N. T., and Bhavnani, R. (2002). The missing globalization puzzle. Working Paper 02/171, IMF, Washington.

Combes, P.-P. (2008). Gravity models. In Durlauf, S. N. and Blume, L. E., editors, The New Palgrave Dictionary of Economics. Palgrave-Macmillan, London, $2^{\text {nd }}$ edition.

Combes, P.-P., Mayer, T., and Thisse, J.-F. (2008). Economic Geography. Princeton University Press, Princeton, New Jersey.

Cox, K. R. (2008). Globalization, uneven development and capital: reflections on reading Thomas Friedman's The World is Flat. Cambridge Journal of Regions, Economy and Society, 1:389-410.

Deardorff, A. (1998). Determinants of Bilateral Trade: Does Gravity Work in a Neoclassical World? The Regionalization of the World Economy, pages 7-22.

Disdier, A. and Head, K. (2008). The puzzling persistence of the distance effect on bilateral trade. Review of Economics and Statistics, 90:37-48.

Eldridge, J. D. and Jones, J. P. (1991). Warped space: A geography of distance decay. The Professional Geographer, 43(4):500-511.

Epstein, P., Howlett, P., and Schulze, M.-S. (2007). Trade, convergence, and globalisation: The dynamics of the international income distribution, 1950-1998. Explorations in Economic History, 44(1):100-113. 
Evenett, S. and Keller, W. (2002). On theories explaining the success of the gravity model. Journal of Political Economy, 110:281-316.

Feenstra, R. C., Markusen, J. R., and Rose, A. K. (1998). Undertstanding the home market effect and the gravity equation: The role of differentiating goods. Working Paper 6804, NBER, Cambridge, Massachusetts.

Feenstra, R. C., Markusen, J. R., and Rose, A. K. (2001). Using the gravity equation to differentiate among alternative theories of trade. Canadian Journal of Economics, 34(2):430-447.

Foster, S. A. (1991). The expansion method: implications for geographic research. The Professional Geographer, 43(2):131-142.

Fotheringham, A. S., Brunsdon, C., and Charlton, M. (2002). Geographically Weighted Regression: The Analysis of Spatially Varying Relationships. John Wiley \& Sons Inc, Chichester.

Frankel, J. A. (2000). Globalization of the economy. Working Paper 7858, NBER, Cambridge, Massachusetts.

Friedman, T. L. (2005). The World is Flat: A Brief History of the Twenty-First Century. Farrar, Straus, \& Giroux, New York.

Greenaway, D. and Milner, D. (2002). Regionalism and gravity. Scottish Journal of Political Economy, 49(5):574-585.

Head, K. and Mayer, T. (2002). Illusory border effects: distance mismeasurement inflates estimates of home bias in trade. Working Paper 01, CEPII, Paris.

Helliwell, J. F. and Verdier, G. (2001). Measuring internal trade distances: A new method applied to estimate provincial border effects in Canada. The Canadian Journal of Economics, 34(4):10241041.

Henderson, D. J. and Millimet, D. L. (2008). Is gravity linear? Journal of Applied Econometrics, 23:137-172.

Huang, R. (2007). Evaluating the real effect of bank branching deregulation: Comparing contiguous counties across US state borders. Journal of Financial Economics, 87:678-705.

Hummels, D. (1999). Have interational transport costs declined? University of Chicago.

Hummels, D. and Levinsohn, J. (1995). Monopolistic competition and international trade: Reconsidering the evidence. Quarterly Journal of Economics, 110(3):799-836. 
Iapadre, L. (2006). Regional integration agreements and the geography of world trade: measurement problems and empirical evidence. In De Lombaerde, P., editor, Assessment and Measurement of Regional Integration, pages 65-85. Routledge, London.

Jones, J. P. (1992). Paradigmatic dimensions of the expansion method. In Jones, J. P. and Casetti, E., editors, Applications of the Expansion Method, pages 32-46. Routledge, London.

Jones, K. and Bullen, N. (1994). Contextual models of urban house prices: a comparison of fixedand random-coefficient models developed by expansion. Economic Geography, 70(3):252-272.

Kali, R. and Reyes, J. (2007). The architecture of globalization: a network approach to international economic integration. Journal of International Business Studies, 38:595-620.

Keeble, D., Oxford, J., and Walker, S. (1988). Peripheral Regions in a Community of Twelve Member States. Office for Official Publications of the European Communities, Luxembourg.

Krugman, P. R. (1996). Regionalism versus multilateralism: analytical notes. In de Melo, J. and Panagariya, A., editors, New Dimensions in Regional Integration, CEPR, chapter 3, pages 58-89. Cambridge University Press, Cambridge.

Kunimoto, K. (1977). Typology of trade intensity indices. Hitotsubashi Journal of Economics, 17(2):15-32.

Leamer, E. E. (1988). Measures of openness. In Baldwin, R. E., editor, Trade Policy Issues and Empirical Analysis, NBER, chapter 6, pages 147-204. The University of Chicago Press, Chicago.

Leamer, E. E. (1997). Access to Western markets and Eastern effort. In Zecchini, S., editor, Lessons from the Economic Transition, Central and Eastern Europe in the 1990s, pages 503-526. Kluwer Academic Publishers, Dordrecht.

Leamer, E. E. (2007). A flat world, a level playing field, a small world after all, or none of the above? A review of Thomas L. Friedman's The World Is Flat. Journal of Economic Literature, 45(1):83-126.

Leamer, E. E. and Levinsohn, J. (1995). International trade theory: The evidence. In Grossman, G. and Rogoff, K., editors, Handbook of International Economics, volume 3, chapter 26, pages 1339-1394. Elsevier.

Linders, G.-J., Burger, M. J., and van Oort, F. G. (2008). A rather empty world: The many faces of distance and the persistent resistance to international trade. Cambridge Journal of Regions, Economy and Society, 1(3):439-458. 
Maddison, A. (2001). The World Economy: A Millenial Perspective. Development Centre Studies, OECD.

McCann, P. (2008). Globalization and economic geography: the world is curved, not flat. Cambridge Journal of Regions, Economy and Society, 1(3):351-370.

McLuhan, M. and Fiore, Q. (1968). War and Peace in the Global Village: An Inventory of the Current Spastic Situations That Could Be Eliminated by More Feedforward. Bantam Books/Random House, New York.

Nitsch, V. (2000a). It's not right, but it's okay: On the measurement of intra-and international trade distances. Unpublished manuscript.

Nitsch, V. (2000b). National borders and international trade: evidence from the European Union. Canadian Journal of Economics, 33(4):1091-1105.

O'brien, R. (1992). Global Financial Integration: The End of Geography. Royal Institute of International Affairs, London.

O'Rourke, K. H. and Williamson, J. G. (2002). When did globalization begin? European Review of Economic History, 6:23-50.

Pritchett, L. (1996). Measuring outward orientation in LDCs: Can it be done? Journal of Development Economics, 49(2):307-335.

Proudman, J., Redding, S., and Bianchi, M. (1997). Is international openness associated with faster economic growth? Working paper, Bank of England.

Quah, D. T. (1996). Regional convergence clusters across Europe. European Economic Review, 40:951-958.

Rauch, J. E. (1999). Networks versus markets in international trade. Journal of International Economics, 48:7-35.

Redding, S. (2002). Specialization dynamics. Journal of International Economics, 58(2):299-334.

Redding, S. and Schott, P. K. (2003). Distance, skill deepening and development: will peripheral countries ever get rich? Journal of Development Economics, 72:515-541.

Redding, S. and Venables, A. (2004). Economic geography and international inequality. Journal of International Economics, 62(1):53-82. 
Rodríguez-Pose, A. and Crescenzi, R. (2008). Mountains in a flat world: Why proximity still matters for the location of economic activity. Cambridge Journal of Regions, Economy and Society, 1(3):371-388.

Rose, A. K. (2000). One money, one market: the effect of common currencies on trade. Economic Policy, 15(30):7-46.

Samuelson, P. (1954). The transfer problem and transport costs, II: Analysis of effects of trade impediments. The Economic Journal, 64(254):264-289.

Schott, P. K. (2004). Across-product versus within-product specialization in international trade. Quarterly Journal of Economics, 119(2):647-678.

Sheppard, E. S. (1984). The distance-decay gravity model debate. In Gaile, G. L. and Willmott, C. J., editors, Spatial Statistics and Models, pages 367-388. D. Reidel Publishing Company.

Stock, J. H. and Watson, M. W. (2008). Heteroskedasticity-robust standard errors for fixed effects panel data regression. Econometrica, 76(1):155-174.

Wei, S.-J. (1996). Intra-national versus international trade: How stubborn are nations in global integration? Technical Report 5531, NBER.

White, H. (1980). A heteroskedasticity-consistent covariance matrix estimator and a direct test for heteroskedasticity. Econometrica, 48(4):817-838.

Wolf, H. C. (2000). Intranational Home Bias in Trade. The Review of Economics and Statistics, 82(4):555-563.

Wonnacott, R. J. (1996). Free-trade agreements: For better or worse? The American Economic Review, 86(2):62-66. 
Table 1: List of countries in the sample

\begin{tabular}{lll}
\hline Albania & Germany & Philippines \\
Algeria & Greece & Poland \\
Argentina & Hong Kong & Portugal \\
Australia & Hungary & Romania \\
Austria & Iceland & Singapore \\
Belgium and Luxembourg & India & South Africa \\
Brazil & Indonesia & South Korea \\
Brunei Darussalam & Ireland & Spain \\
Bulgaria & Israel & Sweden \\
Canada & Italy & Switzerland \\
Chile & Japan & Taiwan \\
China, People's Rep. & Malaysia & Thailand \\
Colombia & Mexico & Tunisia \\
Czechoslovakia, former & Morocco & Turkey \\
Denmark & Netherlands & United Kingdom \\
Ecuador & New Zealand & United States \\
Egypt & Nigeria & USSR, former \\
Finland & Norway & Venezuela \\
France & Pakistan & Yugoslavia, former \\
Gabon & Peru & \\
\hline
\end{tabular}


Table 2: $D G O, D G B C$ and $D G I$, distance-uncorrected and distancecorrected indices $(\%)$

\begin{tabular}{|c|c|c|c|c|c|c|}
\hline Year & $D G O^{\theta=0}$ & $D G O^{\theta=1}$ & $D G B C^{\theta=0}$ & $D G B C^{\theta=1}$ & $D G I^{\theta=0}$ & $D G I^{\theta=1}$ \\
\hline 1967 & 8.03 & 12.13 & 57.66 & 82.42 & 20.30 & 30.41 \\
\hline 1968 & 8.44 & 12.91 & 58.96 & 83.90 & 21.02 & 31.53 \\
\hline 1969 & 8.90 & 13.67 & 58.26 & 84.22 & 21.32 & 32.45 \\
\hline 1970 & 9.53 & 14.65 & 60.38 & 83.21 & 22.34 & 33.30 \\
\hline 1971 & 9.53 & 14.70 & 59.46 & 84.60 & 22.22 & 33.47 \\
\hline 1972 & 9.80 & 15.31 & 61.12 & 86.20 & 22.78 & 34.37 \\
\hline 1973 & 11.04 & 17.34 & 63.97 & 86.67 & 24.76 & 36.83 \\
\hline 1974 & 13.27 & 20.87 & 64.29 & 87.24 & 27.37 & 40.49 \\
\hline 1975 & 12.25 & 18.94 & 62.56 & 88.11 & 26.00 & 38.97 \\
\hline 1976 & 12.76 & 20.02 & 63.04 & 89.04 & 26.58 & 40.13 \\
\hline 1977 & 12.81 & 20.59 & 62.74 & 89.52 & 26.62 & 40.66 \\
\hline 1978 & 12.87 & 21.79 & 65.23 & 90.72 & 27.26 & 42.13 \\
\hline 1979 & 14.18 & 22.81 & 65.55 & 90.69 & 28.73 & 43.38 \\
\hline 1980 & 15.11 & 24.20 & 66.32 & 89.38 & 30.04 & 44.40 \\
\hline 1981 & 14.63 & 24.75 & 66.93 & 89.05 & 29.63 & 44.59 \\
\hline 1982 & 14.07 & 23.33 & 67.57 & 88.69 & 29.02 & 43.27 \\
\hline 1983 & 13.84 & 23.58 & 66.90 & 89.65 & 28.55 & 43.51 \\
\hline 1984 & 14.63 & 25.73 & 67.75 & 90.66 & 29.69 & 45.53 \\
\hline 1985 & 14.25 & 24.92 & 67.33 & 89.78 & 29.10 & 44.48 \\
\hline 1986 & 13.53 & 25.66 & 67.13 & 89.66 & 28.24 & 44.66 \\
\hline 1987 & 13.99 & 26.69 & 68.02 & 90.07 & 28.92 & 45.82 \\
\hline 1988 & 14.18 & 28.25 & 69.47 & 91.44 & 29.53 & 47.56 \\
\hline 1989 & 14.62 & 28.33 & 70.38 & 91.28 & 30.13 & 47.85 \\
\hline 1990 & 14.81 & 27.42 & 70.27 & 90.67 & 30.43 & 47.21 \\
\hline 1991 & 14.52 & 27.84 & 69.63 & 90.82 & 30.14 & 47.58 \\
\hline 1992 & 14.54 & 28.20 & 68.84 & 90.66 & 30.14 & 47.97 \\
\hline 1993 & 14.38 & 29.61 & 67.11 & 90.16 & 29.55 & 48.81 \\
\hline 1994 & 15.25 & 31.12 & 67.03 & 90.15 & 30.32 & 50.11 \\
\hline 1995 & 16.38 & 32.42 & 67.16 & 89.76 & 31.37 & 51.13 \\
\hline 1996 & 16.61 & 30.60 & 67.47 & 89.42 & 31.73 & 49.90 \\
\hline 1997 & 17.51 & 31.63 & 66.90 & 89.08 & 32.47 & 50.67 \\
\hline 1998 & 17.47 & 30.59 & 66.99 & 89.45 & 32.39 & 50.09 \\
\hline 1999 & 17.41 & 31.24 & 67.20 & 89.29 & 32.40 & 50.61 \\
\hline 2000 & 18.85 & 34.37 & 67.70 & 88.78 & 33.74 & 52.80 \\
\hline 2001 & 18.28 & 31.44 & 67.66 & 89.54 & 33.12 & 51.08 \\
\hline 2002 & 18.24 & 30.35 & 66.87 & 89.56 & 32.98 & 50.13 \\
\hline 2003 & 18.78 & 30.38 & 65.89 & 89.48 & 33.19 & 49.91 \\
\hline 2004 & 20.12 & 32.01 & 65.22 & 89.08 & 34.16 & 50.93 \\
\hline 2005 & 20.84 & 32.27 & 67.10 & 88.80 & 35.48 & 50.96 \\
\hline
\end{tabular}


Table 3: Discrepancies between $D B C^{\theta=0}$ and $D B C^{\theta=1}(\%)$, selected countries

\begin{tabular}{|c|c|c|c|c|c|}
\hline \multicolumn{6}{|c|}{ Degree of balanced connection $(D B C)$} \\
\hline \multicolumn{3}{|c|}{ Distance relevant (year 2005) } & \multicolumn{3}{|c|}{ Distance irrelevant (year 2005) } \\
\hline Country & $\theta=0$ & $\theta=1$ & Country & $\theta=0$ & $\theta=1$ \\
\hline Austria & 42.66 & 88.52 & Brazil & 89.48 & 91.37 \\
\hline Belgium & 48.25 & 92.77 & Chile & 88.02 & 81.43 \\
\hline Denmark & 51.30 & 87.58 & China & 97.77 & 79.14 \\
\hline Finland & 48.86 & 86.11 & India & 92.88 & 89.47 \\
\hline Italy & 63.77 & 97.08 & Nigeria & 89.79 & 85.46 \\
\hline Spain & 44.24 & 87.25 & Peru & 90.61 & 92.73 \\
\hline U.S. & 57.59 & 90.51 & South Africa & 77.62 & 80.38 \\
\hline
\end{tabular}


Table 4: Determinants of the distance effect, degree of openness, 1967-2005

\begin{tabular}{|c|c|c|c|c|}
\hline \multirow[b]{2}{*}{ Coefficients } & \multicolumn{4}{|c|}{ Dependent variable: $D O^{\theta=1} / D O^{\theta=0}$} \\
\hline & Model 1 & Model 2 & Model 3 & Model 4 \\
\hline (Intercept) & $\begin{array}{c}-1.456^{* * *} \\
(0.264)\end{array}$ & $\begin{array}{c}-1.454^{* * *} \\
(0.265)\end{array}$ & $\begin{array}{c}-0.732^{* * *} \\
(0.233)\end{array}$ & $\begin{array}{c}-0.652^{* * *} \\
(0.230)\end{array}$ \\
\hline$G D P$ & $\begin{array}{l}0.239^{* * *} \\
(0.018)\end{array}$ & $\begin{array}{l}0.239^{* * *} \\
(0.018)\end{array}$ & & \\
\hline$G D P \_P C$ & & & $\begin{array}{l}0.292^{* * *} \\
(0.024)\end{array}$ & $\begin{array}{l}0.284^{* * *} \\
(0.023)\end{array}$ \\
\hline REMOTE_GDP & $\begin{array}{c}-4.394 \\
(9.764)\end{array}$ & $\begin{array}{l}-3.490 \\
(9.816)\end{array}$ & $\begin{array}{l}-9.103 \\
(10.036)\end{array}$ & $\begin{array}{l}-8.480 \\
(10.103)\end{array}$ \\
\hline CONSTRUCTION & $\begin{array}{c}-0.038^{* *} \\
(0.017)\end{array}$ & $\begin{array}{c}-0.040^{* *} \\
(0.017)\end{array}$ & $\begin{array}{c}-0.035^{* *} \\
(0.017)\end{array}$ & $\begin{array}{c}-0.040^{* *} \\
(0.017)\end{array}$ \\
\hline BASIC_METALS & $\begin{array}{c}-0.034^{* * *} \\
(0.010)\end{array}$ & $\begin{array}{c}-0.032^{* * *} \\
(0.010)\end{array}$ & $\begin{array}{c}-0.023^{* *} \\
(0.010)\end{array}$ & $\begin{array}{c}-0.021^{* *} \\
(0.010)\end{array}$ \\
\hline TEXTILES & $\begin{array}{c}-0.040^{* * *} \\
(0.006)\end{array}$ & $\begin{array}{c}-0.040^{* * *} \\
(0.007)\end{array}$ & $\begin{array}{c}-0.031^{* * *} \\
(0.006)\end{array}$ & $\begin{array}{c}-0.031^{* * *} \\
(0.006)\end{array}$ \\
\hline WOOD_PAPER & $\begin{array}{c}-0.097^{* * *} \\
(0.016)\end{array}$ & $\begin{array}{c}-0.095^{* * *} \\
(0.015)\end{array}$ & $\begin{array}{c}-0.104^{* * *} \\
(0.017)\end{array}$ & $\begin{array}{c}-0.097^{* * *} \\
(0.017)\end{array}$ \\
\hline METAL_PRODUCTS & $\begin{array}{c}0.016 \\
(0.032)\end{array}$ & $\begin{array}{c}0.013 \\
(0.032)\end{array}$ & $\begin{array}{l}0.054^{*} \\
(0.032)\end{array}$ & $\begin{array}{c}0.060^{*} \\
(0.031)\end{array}$ \\
\hline CHEMICALS & $\begin{array}{c}-0.143^{* * *} \\
(0.028)\end{array}$ & $\begin{array}{c}-0.142^{* * *} \\
(0.028)\end{array}$ & $\begin{array}{c}-0.135^{* * *} \\
(0.028)\end{array}$ & $\begin{array}{c}-0.134^{* * *} \\
(0.028)\end{array}$ \\
\hline MINING & $\begin{array}{c}-0.004 \\
(0.003)\end{array}$ & $\begin{array}{c}-0.004 \\
(0.003)\end{array}$ & $\begin{array}{r}-0.005 \\
(0.003)\end{array}$ & $\begin{array}{r}-0.004 \\
(0.003)\end{array}$ \\
\hline ENERGY & $\begin{array}{c}-0.021^{* * *} \\
(0.004)\end{array}$ & $\begin{array}{c}-0.020^{* * *} \\
(0.003)\end{array}$ & $\begin{array}{c}-0.016^{* * *} \\
(0.003)\end{array}$ & $\begin{array}{c}-0.015^{* * *} \\
(0.003)\end{array}$ \\
\hline AGRICULTURE & $\begin{array}{l}0.009^{* *} \\
(0.005)\end{array}$ & $\begin{array}{l}0.009^{* *} \\
(0.005)\end{array}$ & $\begin{array}{l}0.009^{* *} \\
(0.005)\end{array}$ & $\begin{array}{c}0.009^{*} \\
(0.005)\end{array}$ \\
\hline FOOD_PRODUCTS & $\begin{array}{c}0.004 \\
(0.004)\end{array}$ & $\begin{array}{c}0.004 \\
(0.004)\end{array}$ & $\begin{array}{c}0.008^{* *} \\
(0.004)\end{array}$ & $\begin{array}{c}0.009^{* *} \\
(0.004)\end{array}$ \\
\hline MISC & $\begin{array}{l}0.017^{* * *} \\
(0.005)\end{array}$ & $\begin{array}{l}0.017^{* * *} \\
(0.005)\end{array}$ & $\begin{array}{l}0.020^{* * *} \\
(0.005)\end{array}$ & $\begin{array}{l}0.020^{* * *} \\
(0.004)\end{array}$ \\
\hline YRTA & $\begin{array}{c}-0.003^{* * *} \\
(0.001)\end{array}$ & $\begin{array}{c}-0.003^{* * *} \\
(0.001)\end{array}$ & $\begin{array}{c}-0.002^{* *} \\
(0.001)\end{array}$ & $\begin{array}{c}-0.002^{* *} \\
(0.001)\end{array}$ \\
\hline$E U$ & $\begin{array}{c}-0.129^{* * *} \\
(0.016)\end{array}$ & & $\begin{array}{c}-0.161^{* * *} \\
(0.018)\end{array}$ & \\
\hline NAFTA & $\begin{array}{c}-0.077^{* * *} \\
(0.017)\end{array}$ & & $\begin{array}{c}-0.042^{* * *} \\
(0.015)\end{array}$ & \\
\hline$A S E A N$ & $\begin{array}{c}-0.112^{* *} \\
(0.044)\end{array}$ & & $\begin{array}{c}-0.026 \\
(0.045)\end{array}$ & \\
\hline MERCOSUR & $\begin{array}{c}-0.016 \\
(0.017)\end{array}$ & & $\begin{array}{c}0.015 \\
(0.018)\end{array}$ & \\
\hline RTA & & $\begin{array}{c}-0.102^{* * *} \\
(0.013)\end{array}$ & & $\begin{array}{c}-0.091^{* * *} \\
(0.014)\end{array}$ \\
\hline $\bar{R}^{2}$ & 0.197 & 0.194 & 0.185 & 0.180 \\
\hline$\sigma$ & 0.239 & 0.239 & 0.240 & 0.241 \\
\hline$F$ & 180.629 & 187.660 & 177.718 & 183.929 \\
\hline$p$ & 0.000 & 0.000 & 0.000 & 0.000 \\
\hline Log-likelihood & 72.298 & 68.898 & 56.228 & 49.052 \\
\hline$N$ & 2,301 & 2,301 & 2,301 & 2,301 \\
\hline
\end{tabular}

$*, * *$ and ${ }^{* * *}$ denote significance at $10 \%, 5 \%$, and $1 \%$ significance levels, respectively. Standard errors are reported in parentheses. 
Table 5: Determinants of the distance effect, degree of balanced connection, 1967-2005

\begin{tabular}{|c|c|c|c|c|}
\hline \multirow[b]{2}{*}{ Coefficients } & \multicolumn{4}{|c|}{ Dependent variable: $D B C^{\theta=1} / D B C^{\theta=0}$} \\
\hline & Model 1 & Model 2 & Model 3 & Model 4 \\
\hline (Intercept) & $\begin{array}{l}4.639^{* * *} \\
(0.460)\end{array}$ & $\begin{array}{l}4.521^{* * *} \\
(0.438)\end{array}$ & $\begin{array}{l}3.096^{* * *} \\
(0.400)\end{array}$ & $\begin{array}{l}2.419^{* * *} \\
(0.450)\end{array}$ \\
\hline$G D P$ & $\begin{array}{c}-0.214^{* * *} \\
(0.032)\end{array}$ & $\begin{array}{c}-0.202^{* * *} \\
(0.031)\end{array}$ & & \\
\hline$G D P \_P C$ & & & $\begin{array}{c}-0.166^{* * *} \\
(0.036)\end{array}$ & $\begin{array}{c}-0.091^{* *} \\
(0.039)\end{array}$ \\
\hline REMOTE_GDP & $\begin{array}{r}-43.836^{*} \\
(26.027)\end{array}$ & $\begin{array}{c}-30.311 \\
(28.410)\end{array}$ & $\begin{array}{c}-39.619 \\
(26.365)\end{array}$ & $\begin{array}{c}-26.271 \\
(28.935)\end{array}$ \\
\hline CONSTRUCTION & $\begin{array}{l}0.077^{* * *} \\
(0.026)\end{array}$ & $\begin{array}{l}0.108^{* * *} \\
(0.026)\end{array}$ & $\begin{array}{l}0.075^{* * *} \\
(0.026)\end{array}$ & $\begin{array}{l}0.108^{* * *} \\
(0.027)\end{array}$ \\
\hline BASIC_METALS & $\begin{array}{l}0.119^{* * *} \\
(0.021)\end{array}$ & $\begin{array}{l}0.127^{* * *} \\
(0.021)\end{array}$ & $\begin{array}{l}0.110^{* * *} \\
(0.021)\end{array}$ & $\begin{array}{l}0.119^{* * *} \\
(0.021)\end{array}$ \\
\hline TEXTILES & $\begin{array}{l}0.069^{* * *} \\
(0.016)\end{array}$ & $\begin{array}{l}0.073^{* * *} \\
(0.016)\end{array}$ & $\begin{array}{l}0.060^{* * *} \\
(0.015)\end{array}$ & $\begin{array}{l}0.063^{* * *} \\
(0.016)\end{array}$ \\
\hline WOOD_PAPER & $\begin{array}{l}0.072^{* * *} \\
(0.026)\end{array}$ & $\begin{array}{c}0.011 \\
(0.019)\end{array}$ & $\begin{array}{l}0.091^{* * *} \\
(0.027)\end{array}$ & $\begin{array}{l}0.037^{* *} \\
(0.018)\end{array}$ \\
\hline METAL_PRODUCTS & $\begin{array}{l}0.258^{* * *} \\
(0.061)\end{array}$ & $\begin{array}{l}0.193^{* * *} \\
(0.054)\end{array}$ & $\begin{array}{l}0.181^{* * *} \\
(0.051)\end{array}$ & $\begin{array}{c}0.089^{* *} \\
(0.040)\end{array}$ \\
\hline CHEMICALS & $\begin{array}{c}-0.151^{* * *} \\
(0.037)\end{array}$ & $\begin{array}{c}-0.127^{* * *} \\
(0.034)\end{array}$ & $\begin{array}{c}-0.174^{* * *} \\
(0.037)\end{array}$ & $\begin{array}{c}-0.161^{* * *} \\
(0.034)\end{array}$ \\
\hline MINING & $\begin{array}{c}-0.028^{* * *} \\
(0.008)\end{array}$ & $\begin{array}{c}-0.026^{* * *} \\
(0.008)\end{array}$ & $\begin{array}{c}-0.030^{* * *} \\
(0.008)\end{array}$ & $\begin{array}{c}-0.029^{* * *} \\
(0.008)\end{array}$ \\
\hline ENERGY & $\begin{array}{l}0.071^{* * *} \\
(0.016)\end{array}$ & $\begin{array}{l}0.074^{* * *} \\
(0.019)\end{array}$ & $\begin{array}{l}0.067^{* * *} \\
(0.016)\end{array}$ & $\begin{array}{l}0.069^{* * *} \\
(0.019)\end{array}$ \\
\hline AGRICULTURE & $\begin{array}{l}0.055^{* * *} \\
(0.008)\end{array}$ & $\begin{array}{l}0.060^{* * *} \\
(0.009)\end{array}$ & $\begin{array}{l}0.061^{* * *} \\
(0.009)\end{array}$ & $\begin{array}{l}0.070^{* * *} \\
(0.011)\end{array}$ \\
\hline FOOD_PRODUCTS & $\begin{array}{c}0.016^{*} \\
(0.009)\end{array}$ & $\begin{array}{c}0.012 \\
(0.010)\end{array}$ & $\begin{array}{c}0.010 \\
(0.009)\end{array}$ & $\begin{array}{c}0.003 \\
(0.010)\end{array}$ \\
\hline MISC & $\begin{array}{c}-0.036^{* * *} \\
(0.011)\end{array}$ & $\begin{array}{c}-0.043^{* * *} \\
(0.011)\end{array}$ & $\begin{array}{c}-0.040^{* * *} \\
(0.011)\end{array}$ & $\begin{array}{c}-0.047^{* * *} \\
(0.012)\end{array}$ \\
\hline YRTA & $\begin{array}{c}-0.001 \\
(0.002)\end{array}$ & $\begin{array}{c}0.002 \\
(0.002)\end{array}$ & $\begin{array}{c}-0.004^{* *} \\
(0.002)\end{array}$ & $\begin{array}{r}-0.003^{*} \\
(0.002)\end{array}$ \\
\hline$E U$ & $\begin{array}{l}0.343^{* * *} \\
(0.065)\end{array}$ & & $\begin{array}{l}0.359^{* * *} \\
(0.064)\end{array}$ & \\
\hline NAFTA & $\begin{array}{l}0.135^{* * *} \\
(0.022)\end{array}$ & & $\begin{array}{l}0.093^{* * *} \\
(0.020)\end{array}$ & \\
\hline$A S E A N$ & $\begin{array}{c}-1.623^{* * *} \\
(0.425)\end{array}$ & & $\begin{array}{c}-1.669^{* * *} \\
(0.436)\end{array}$ & \\
\hline MERCOSUR & $\begin{array}{l}0.114^{* *} \\
(0.050)\end{array}$ & & $\begin{array}{c}0.098^{*} \\
(0.051)\end{array}$ & \\
\hline RTA & & $\begin{array}{c}-0.051 \\
(0.059)\end{array}$ & & $\begin{array}{c}-0.062 \\
(0.061)\end{array}$ \\
\hline$R^{2}$ & 0.271 & 0.171 & 0.256 & 0.152 \\
\hline$\sigma$ & 0.368 & 0.392 & 0.372 & 0.397 \\
\hline$F$ & 85.946 & 75.111 & 83.523 & 72.729 \\
\hline$p$ & 0.000 & 0.000 & 0.000 & 0.000 \\
\hline Log-likelihood & -924.798 & -1072.690 & -949.252 & -1098.929 \\
\hline$N$ & 2,301 & 2,301 & 2,301 & 2,301 \\
\hline
\end{tabular}

$*, * *$ and ${ }^{* * *}$ denote significance at $10 \%, 5 \%$, and $1 \%$ significance levels, respec-

tively. Standard errors are reported in parentheses. 
Figure 1: Degree of openness (DGO), degree of balanced connection (DGBC), and degree of integration (DGI), 1967-2005
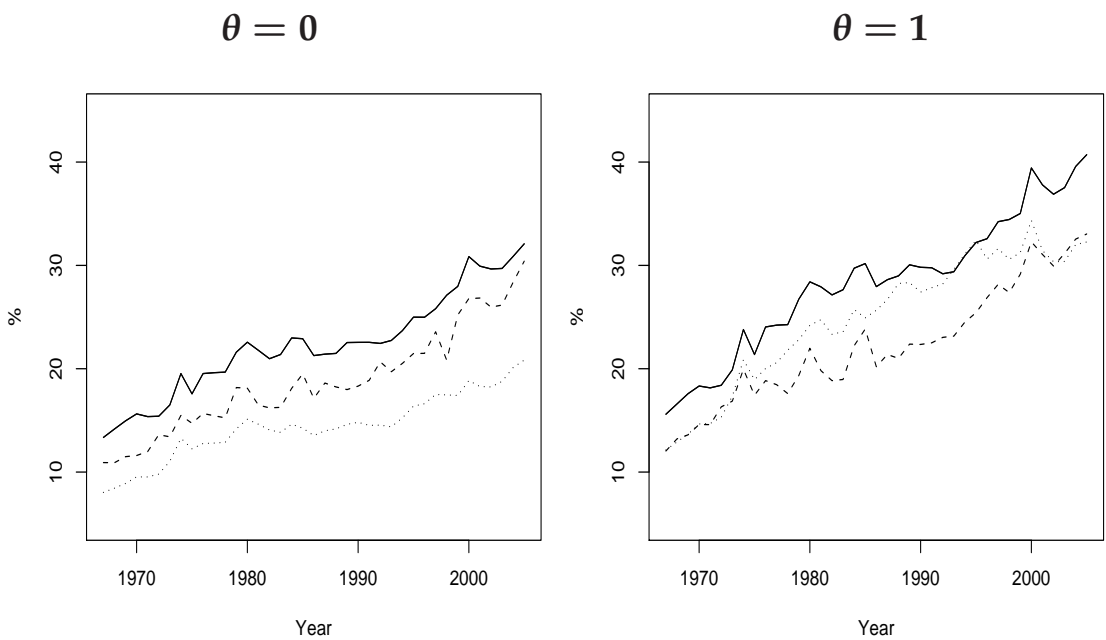

(a) Degree of openness
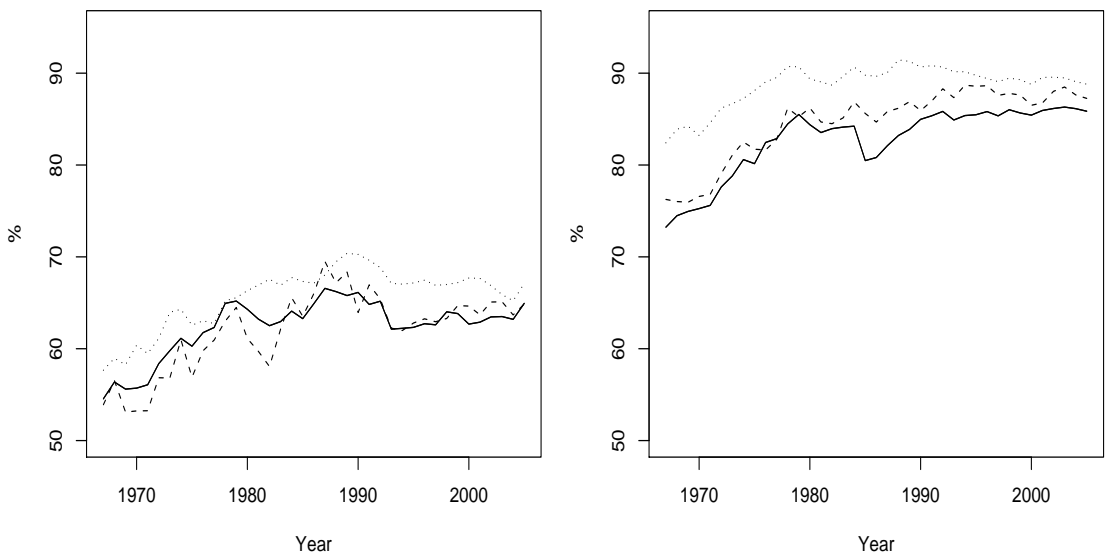

(b) Degree of balanced connection
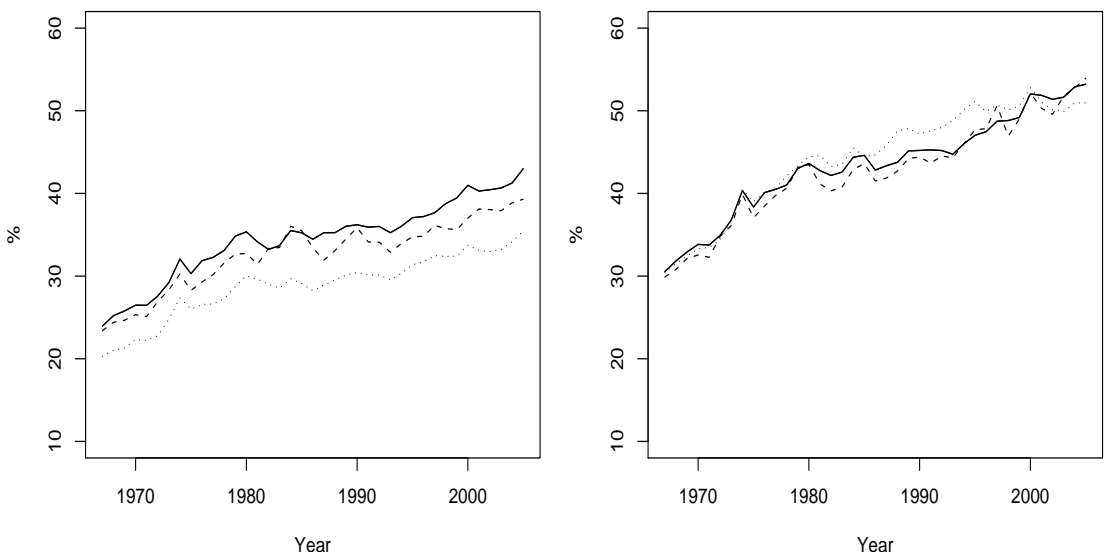

(c) Degree of integration 
Figure 2: The role of distance, time trend (1967-2005)

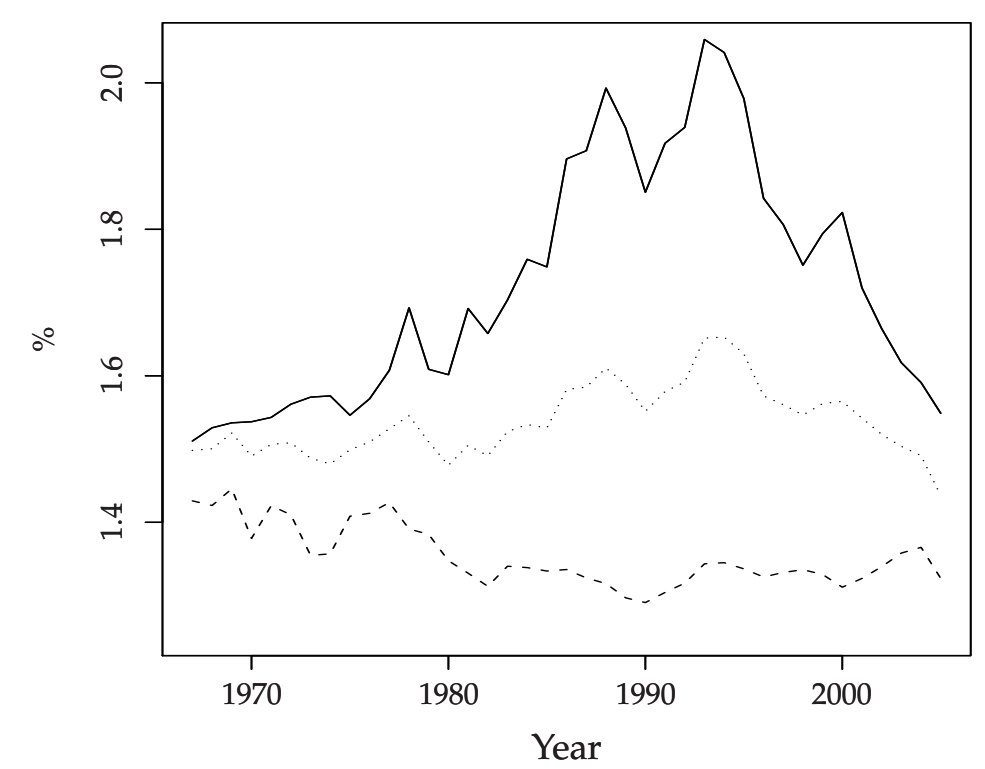

$D G O^{\theta=1} / D G O^{\theta=0}$------ $D G B C^{\theta=1} / D G B C^{\theta=0} \ldots \ldots . . D G I^{\theta=1} / D G I^{\theta=0}$ 